\title{
Tapping into technology and the biodiversity informatics revolution: updated terrestrial mammal list of Angola, with new records from the Okavango Basin
}

\author{
Peter J. Taylor ${ }^{1,2,3}$, Götz Neef ${ }^{3}$, Mark Keith ${ }^{3,4}$, Sina Weier ${ }^{1,3}$, \\ Ara Monadjem ${ }^{5,6}$, Daniel M. Parker ${ }^{3,7,8}$
}

I South African Research Chair on Biodiversity Value \& Change and Core Team Member of the Centre for Invasion Biology, University of Venda, Thohoyandou 0950, South Africa 2 School of Life Sciences, University of KwaZulu-Natal Private Bag X54001, Durban 4000, South Africa 3 National Geographic Okavango Wilderness Project, Wild Bird Trust, South Africa 4 Eugène Marais Chair of Wildlife Management, Mammal Research Institute, University of Pretoria, Private Bag $\times 20$, Hatfield, Pretoria, 0028, South Africa 5 Department of Biological Sciences, University of Swaziland, Private Bag 4, Kwaluseni, Swaziland 6 Mammal Research Institute, Department of Zoology \& Entomology, University of Pretoria, Private Bag x20, Hatfield, Pretoria, 0028, South Africa 7 School of Biology and Environmental Sciences, University of Mpumalanga, Private Bag X11283, Nelspruit, 1200, South Africa 8 Wildlife and Reserve Management Research Group, Department of Zoology and Entomology, Rhodes University, Grahamstown, 6140, South Africa

Corresponding author: Peter J. Taylor (peter.taylor.univen@gmail.com)

Academic editor: P. Stoev | Received 18 April 2018 | Accepted 18 June 2018 | Published 2 August 2018

http://zoobank.org/AA00E58B-C110-450E-A3F3-42ADFB890F18

Citation: Taylor PJ, Neef G, Keith M, Weier S, Monadjem A, Parker DM (2018) Tapping into technology and the biodiversity informatics revolution: updated terrestrial mammal list of Angola, with new records from the Okavango Basin. ZooKeys 779: 51-88. https://doi.org/10.3897/zookeys.779.25964

\begin{abstract}
Using various sources, including the Global Biodiversity Information Facility (GBIF), published literature, recent (2015-2017) collections, as well as bat detector and camera trap surveys with opportunistic sightings and live capture in the upper Okavango catchment in central Angola, we present an updated mammal checklist of 275 species from 15 different orders for Angola (including the Cabinda region). Recent surveys (captures and bat detectors) of small mammals from the upper Okavango catchment yielded 46 species (33 species of bats, ten species of rodents and three species of shrews). One bat (Pipistrellus rusticus, rusty pipistrelle); two rodents (Mus setzeri, Setzer's mouse and Zelotomys woosnami, Woosnam's
\end{abstract}

Copyright Peter J. Taylor et al. This is an open access article distributed under the terms of the Creative Commons Attribution License (CC BY 4.0), which permits unrestricted use, distribution, and reproduction in any medium, provided the original author and source are credited. 
broad-faced mouse) and one shrew (Suncus varilla, lesser dwarf shrew) were captured for the first time, in Angola. While our species lists of bats conformed to predicted totals, terrestrial small mammals were under sampled, with only 13 species recorded by our trapping survey compared to a total of 42 shrew and rodent species expected based on GBIF records for the central Angolan highlands. Seven terrestrial small mammal species (one shrew and six rodents) are endemic to the central and western Angolan highlands but none of these were captured in our survey. The bat detector surveys added three further bat species to the country list: Pipistrellus hesperidus, Kerivoula argentata, and Mops midas. Camera trap surveys and opportunistic sightings in the upper Okavango catchment in 2016 yielded a total of 35 species of medium-large mammals, from 17 families, although all of these had been reported previously in Angola. GBIF proved to be an excellent source of biodiversity data for Angolan mammals, most importantly for documenting dramatic historical range changes of larger mammals such as the sable (Hippotragus niger niger), Kirk's sable (H. niger kirkii) and the giant sable (H. niger variani).

\section{Keywords}

Angola, checklist, Global Biodiversity Information Facility, mammals, Okavango Basin, scientific collections

\section{Introduction}

Country species checklists and distribution maps for key taxa such as mammals represent a critical step in national efforts towards reaching international (e.g., the Convention on Biological Diversity) and national biodiversity targets and planning for conservation management and sustainable development at regional and local levels. Rapid advances in biodiversity informatics leading to huge volumes of reliable historical and recent occurrence data through public portals such as the Global Biodiversity Information Facility (https://www.gbif.org) make it possible to conduct taxonomic and conservation biodiversity assessments and compile reliable annotated species lists even for poorly known countries and regions (Soberón and Peterson 2004; Beaman and Cellinese 2012; Coetzer 2012; Wieczorek et al. 2012).

At the same time, advances in technology such as camera traps and microphones (including bat detectors) and associated analytical tools are facilitating rapid and efficient field inventories of groups such as larger mammals, bats, birds, crickets, and amphibians. In many cases, acoustic systems have been developed for automated species classification of huge volumes of call data. In the case of bats, echolocation calls are not songs, making the identification to species from bat calls a challenging exercise that requires suitable cross-testing of results using reliably identified calls, e.g., from captured and released individuals (Barclay 1999; Taylor et al. 2013; Monadjem et al. 2017; Rydell et al. 2017). Similarly, camera traps have enabled efficient and comprehensive surveys of medium and large-sized mammals and other groups (Stein et al. 2008; Tobler et al. 2008; Rovero and Marshall 2009; Rovero et al. 2014).

The objectives of this study were firstly to consolidate available data to compile an updated species checklist of terrestrial mammals of Angola, and secondly to add 
to this list the results of recent surveys of mammals in the poorly surveyed Okavango catchment area of the central highlands of Angola, using both live capture and remote camera trap and acoustic techniques.

Brief historical overview of $\mathbf{m}$ the south-western quarter of Angola in the American Museum of Natural History from the Vernay-Lang (conducted in 1925) and Phipps-Bradley (in 1932) expeditions, Hill and Carter (1941) listed a total of 223 species of mammals for Angola, including 13 shrews (Soricomorpha), one hedgehog (Erinaceomorpha), one golden mole and one otter shrew (Afrosoricida), two elephant shrews (Macroscelidea), one aardvark (Tubulidentata), two pangolins (Pholidota), 53 bats (Chiroptera), 10 primates (Primates), two hares (Lagomorpha), 66 rodents (Rodentia), 36 carnivores, one elephant (Proboscidea), two hyraxes (Hyracoidea) and 32 ungulates (four Perissodactyla and 28 Artiodactyla). Subsequent to this publication, Angola has been largely neglected in terms of mammal survey effort. For example, those who led the Smithsonian Institution's ambitious African Mammal Project (1961-1972), which collected 63,213 voucher specimens from throughout Africa and led to the definitive "Mammals of Africa: An Identification Guide" (Meester and Setzer 1971), did not visit Angola at all (Schmidt et al. 2008). Crawford-Cabral and co-authors compiled a database of just under 10,000 records (hosted by the University of Lisbon, Instituto de Investigação Científica Tropical in Portugal) mainly from 1930-1980 of 140 species and subspecies of carnivores, ungulates, and rodents collected from Angola (CrawfordCabral 1998; Crawford-Cabral and Simóes 1987, 1988; Crawford-Cabral and Veríssimo 2005).

The Lubango Museum, originally housed by Instituto de Investigação Científica de Angola (IICA) and currently housed at the the Instituto Superior da Ciências e Educação (ISCED) comprises about 4,000 mammal specimens of at least 123 species from Angola (https://www.gbif.org/publisher/975daf99-f28c-4201-86f2-2bfce0cba085). Another important museum in Angolan history is that established in Dundo. This was a relatively well-stocked museum and was in an important location (in the far northeast) for tropical species. There are at least two important papers by A Monard in 1931 and 1935 (cited in Hayman 1963) that detail the bat species in that collection (as well as other mammals). The small mammals in this collection were reviewed by Hayman (1963) and he mentioned 602 specimens that he examined (apparently these were shipped to him in London) belonging to 91 species and subspecies (including some 14 not previously reported for Angola).

It is little appreciated that Angola was actually relatively well known compared with East Africa until the turn of the $20^{\text {th }}$ century. Early explorers and scientists such as Bocage made enormous contributions. Bocage described 25 Angolan taxa based on new collections between 1878 and 1890, and seven Angolan taxa were named after him by other scientists (Hill and Carter 1941). Of the taxa described by Bocage, although most have been relegated to synonyms or subspecies in current lists, at least eight currently recognized Angolan mammals were named by him: the Angolan fruit bats Epomophorus angolensis and Epomops dobsoni, the murid rodents Myomyscus 


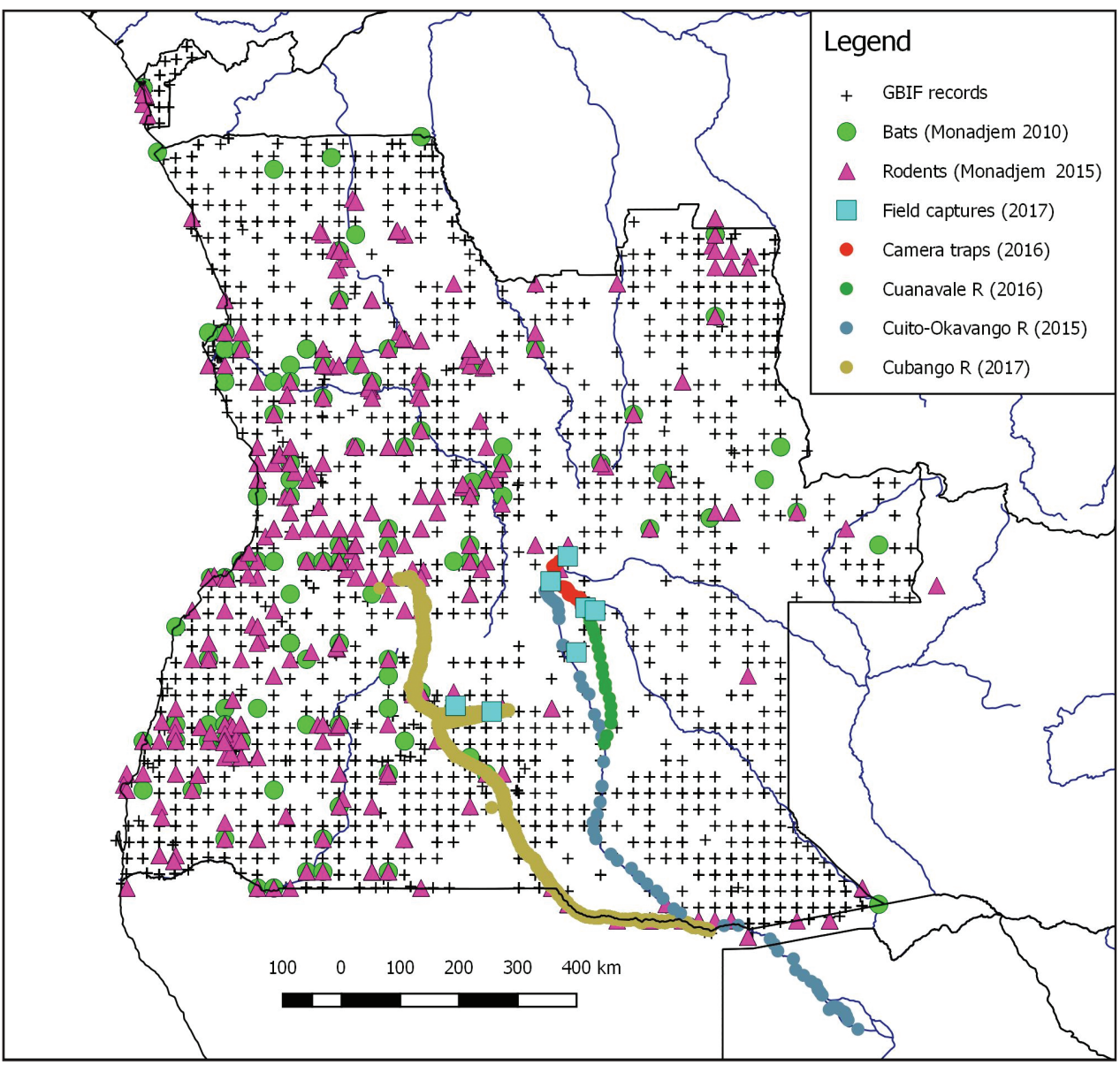

Figure I. Map of Angola showing spatial occurrence of mammal records obtained from various sources, including the present study which reported on captures of small mammals and acoustic recordings of the echolocation calls of bats. Although the Cuito-Okavango River trip of 2015 extended beyond Angola into Namibia and Botswana, there were no species identified from acoustic data in Namibia and Botswana that were not also detected in Angola.

angolensis and Otomys anchietae, the squirrel Funisciurus bayoni, the gerbil Gerbilliscus validus, the genet Genetta angolensis and the mongoose Herpestes flavescens.

Notwithstanding changes in taxonomy and the relative lack of survey effort, the list of species known to occur in Angola has increased, particularly in the case of small mammals. A relatively recent synthesis of Angolan murid rodents was published by Crawford-Cabral (1998) after an older synthesis of bats (Crawford-Cabral 1986). More recently, biogeographical and taxonomic syntheses of African bats (Monadjem et al. 2010a) and rodents (Monadjem et al. 2015) have listed 60 bat species and 78 rodent species from Angola, representing species richness increases of $13 \%$ and $18 \%$, respectively, in comparison to Hill and Carter (1941). 


\section{Materials and methods}

\section{Updating of mammal list for Angola}

We combined records from the literature (Hill and Carter 1941; Hayman 1963; CrawfordCabral 1986, 1998; Crawford-Cabral and Simôes 1987, 1988; Crawford-Cabral and Veríssimo 2005; Monadjem et al. 2010a, 2015) with records obtained from a search of the GBIF portal (www.gbif.org) conducted on 18 December 2017 (GBIF.org 2017), which yielded 14,275 records based on 31 databases (Suppl. material 1). The two main institutions contributing data were the Instituto de Investigação Científica Tropical in Portugal (8,977 records) which incorporates the works of Crawford-Cabral (1998); Crawford-Cabral and Simóes $(1987,1988)$ and Crawford-Cabral and Veríssimo (2005), and the American Museum of Natural History (2,240 records), which incorporates the survey of Hill and Carter (1941). Other important contributors include the Field Museum of Natural History (1,223 records) and The Natural History Museum in London (895 records). Together, these four databases comprised $93 \%$ of all records. We added records from the 2016 collection of 68 small mammals (bats, rodents and shrews) from the Okavango catchment of Angola deposited in the Durban Natural Science Museum (DNSM). The DNSM mammal collection also yielded an additional 14 records of Angolan rodents collected by S. Eiseb and J. Jarvis. Finally, we also added records of bat species determined by acoustic bat detector and capture surveys, shrews and rodents by live trapping methods and medium to large mammals recorded by camera traps supplemented with verifiable opportunistic sightings or signs.

To compile an updated species list based on the above sources, we adopted the taxonomy of Wilson and Reeder (2005) or more recent taxonomic treatments for certain groups, e.g., Monadjem et al. (2010a) and the 2016 African Chiroptera Report for bats (ACR 2016), Monadjem et al. (2015) and Denys et al. (2017) for rodents, and species accounts from all volumes of the series on Mammals of Africa (Kingdon et al. 2013a). We also tested the current taxonomic validity of each name using the Interagency Taxonomic Information System (www.itis.org) and the Mammal Diversity Database of the American Society of Mammalogists (Mammal Diversity Database 2018 https://mammaldiversity. org). Species of dubious occurrence were defined as those having only a single record and/ or collector, no clear basis for identification, occurring well outside their known range, and not included in authoritative texts for Angola (Hill and Carter 1942; Hayman 1963; Crawford-Cabral 1986; Crawford-Cabral 1998; Crawford-Cabral and Simões 1987; 1988; Crawford-Cabral and Veríssimo 2005; Monadjem et al. 2010a, 2015). Dubious species were flagged as such, including the reason for their exclusion. As mentioned above, bat species records based only on acoustic data were also added to this list.

\section{Sampling of upper Okavango catchment region}

Sampling of small mammals from the highlands of Angola using both capture and acoustic techniques was carried out in 2013 (acoustic only), 2015 (acoustic only), 2016 (capture and acoustic) and 2017 (acoustic only). 


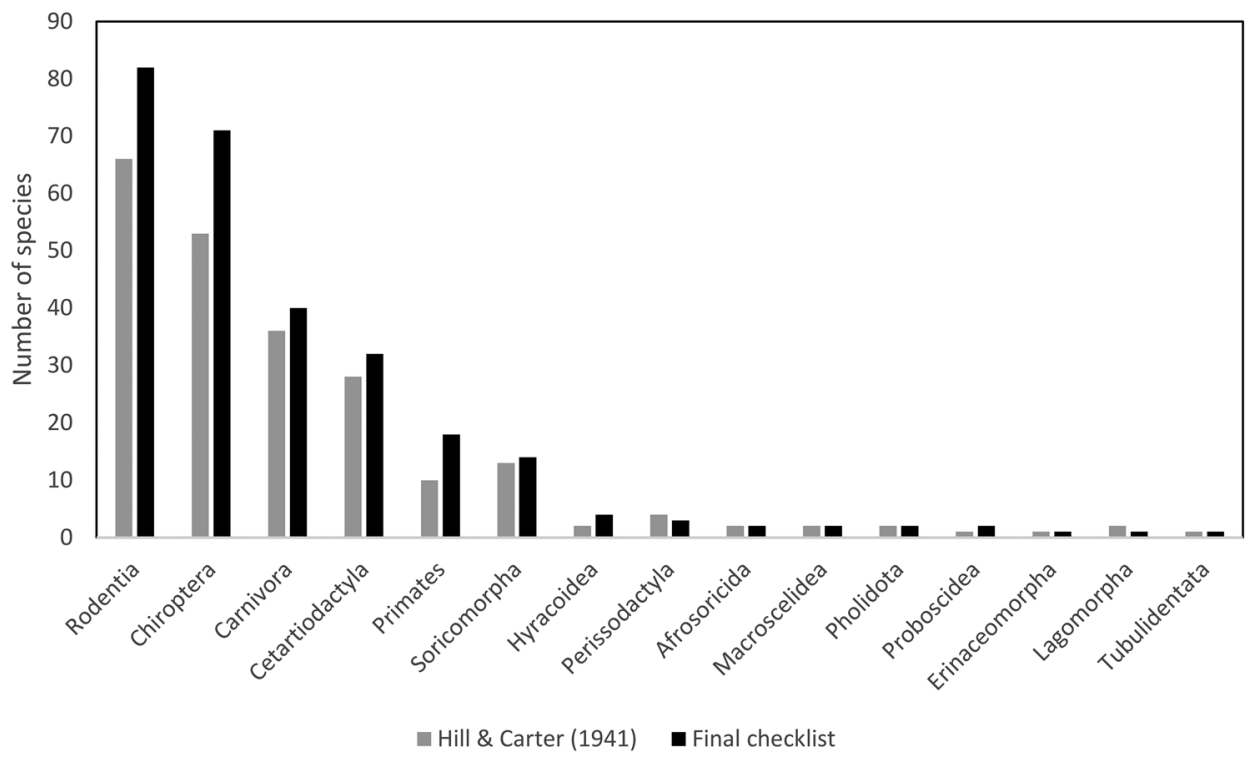

Figure 2. Histogram summarising species number of Angolan terrestrial mammals per order based on Hill and Carter (1943) and the current study.

Capture survey. Between 16 and 22 March 2016, and 29 October and 4 November 2016, bats were captured using one to three mist nets (Ecotone; $6 \mathrm{~m}, 9 \mathrm{~m}$ and 12 m) set per night, a two-bank harp trap ("Austharp", Faunatech), and via searches for roosting bats, e.g., under the loose bark of trees. During the two 2016 field periods, as well as opportunistically on other occasions, shrews and rodents were captured using standard Sherman live-traps, usually $25-30$ per night, set 5-10 m apart in a line. Some shrews were captured in the herpetofauna drift fence arrays. Two bats were collected opportunistically in 2013 and 2016 by W. Conradie.

Acoustic recordings of bats. Using four different bat detectors, we obtained recordings for a total of 208 detector-nights between 2015 and 2017. Apart from monitoring of several point localities, regular (mostly nightly) acoustic monitoring was carried out during three canoe river journeys down the length of the Cuanavale, Cuito, Cubango and Okavango Rivers, totalling a 2,744 km transect. During the 2015 field season, passive acoustic recordings were obtained with an EM3 bat detector (Wildlife Acoustics, Concorde, USA) for 75 nights (between 23 May and 18 September 2015) during a river expedition starting at the Cuito source and continuing to the Okavango Delta. During the early 2016 field season, passive acoustic recordings of bat echolocation calls were obtained using two Song Meter SM2BAT+ bat detectors (Wildlife Acoustics) and an ANABAT SD2 bat detector (Titley Electronics). Passive recording was carried out for six nights in March 2016 with an SM2BAT+ detector and three nights with ANABAT SD2 (in both cases between 15 and 21 March 2016), from the Cuito and Cuanavale source areas, Cuchi Gorge and Samboana Village. Additionally, 
recordings were obtained for 43 nights in total (between 17 February and 4 April 2016), of which 37 nights yielded calls, during a river trip from the source of Cuanavale River to its confluence with the Cuito River. Passive recordings were obtained between 21 October and 4 November 2016 (eight nights) using an SM2BAT + detector, from 27 October to 4 November 2016 (10 nights) with an ANABAT SD2 detector and from 27 October to 2 November 2016 (six nights) with an EM3 detector. During the late 2016 season, recordings focussed on the Cuanavale and Saliakwembo source areas. During 2017, recordings were taken for a period of 1-2 hours nightly for a total of 51 nights with an ANABAT SD1 detector during a river trip down the Cubango River.

The following approach was used to identify bat calls to species or species-groups. Call analysis and identification was undertaken independently by three observers (PJT, MK and DP) although consensus was later obtained on the definition of call parameters for each species after extensive consultation and comparison of calls by PJT. Based on this, a final species list was derived by PJT (Table 1). Using Kaleidoscope Pro software (Wildlife Acoustics), the wave files collected with two SMBAT2+ detectors during the early 2016 season (February to April 2016), both from the Cuanavale River transect and from recordings by PJT in the Cuanavale and Cuito source areas, were firstly converted to zero-crossing (ANABAT) files and then identified manually by PJT using AnalookW software (version 4.1t, Chris Corbin, www.hoarybat.com), for comparison with zero-crossing ANABAT calls obtained directly from ANABAT SD1 and SD2 detectors. The latter included recordings from a SD2 bat detector from the Cuanavale and Cuito source lakes area and Cuchi Gorge in early 2016, as well as those from an Anabat SD1 detector during the 2017 transect of the Cubango River. Identifications were based on reference calls obtained both from ANABAT calls from captured and field-identified individuals that were subsequently released, as well as from standard references (Monadjem et al. 2010, 2017; Happold and Happold 2013; Taylor et al. 2013) and unpublished call data (Taylor, unpublished, Monadjem, unpublished). Using the same identification criteria, calls recorded from the Cuanavale and Saliakembo source lakes in late 2016 using EM3, SM2 + and Anabat SD2 detectors were identified by MK, while calls recorded with the EM3 detector during the 2015 transect of the Cuito and Okavango Rivers were identified by DP using a different software (SonoBat). After extensive comparisons of calls and consultation between PJT, MK, and DP, PJT derived a standard list of putative bat species. This library of identified calls is available on request from PJT.

Camera trapping. The medium and large mammal surveys were conducted using two systematic camera-trapping assessments during 2016. The first camera trapping survey ran between February and March 2016 (936 trap nights) and the second ran between July and November 2016 (1,349 trap nights).

In the first camera trapping survey, two sites near the southern end of the Bie and Moxico provinces were sampled using linear transects. Transect 1 (north-west orientation along the Cuanavale and Cuando Rivers) was approximately $56 \mathrm{~km}$ long and was separated by ca. $20 \mathrm{~km}$ from transect 2 (south-east orientation just south of the town 
of Munhango) which was $50 \mathrm{~km}$ long. We sampled 19 camera stations along transect 1 and 20 camera stations along transect 2, with each station spaced ca. $3 \mathrm{~km}$ (range: 2-4 km) apart. One camera trap was placed at each station and was either a Cuddeback C2 $(\mathrm{n}=11)$, E3 $(\mathrm{n}=8)$ (Non-Typical, Inc. Green Bay, Wisconsin) or Bushnell Trophy Cam Aggressor HD ( $\mathrm{n}=20)$ (Bushnell Outdoor Products, Cody, Kansas). Cameras were placed on animal paths about $30 \mathrm{~cm}$ high on the base of the tree or on a stake placed in the ground to maximize photographic captures of the full range of mammalian body sizes (Mann et al. 2015). Cameras were set to take three sequential photographs per trigger, with an interval of one minute between trigger events. Sensitivity of the sensor was set on medium (normal) and picture quality was set to 5MP. Cameras were operational for 24 hours a day and were checked only upon collection.

The second camera trapping survey employed a similar approach. However, in this survey 17 camera stations were sampled along the Cuanavale River south-east from the village of Tchijanga towards the Quembo River. The transect was approximately $120 \mathrm{~km}$ long and camera traps (13 Cuddeback and four Bushnell) were again placed on well used animal paths, but with no specific distance between each camera station (range: $1-20 \mathrm{~km}$ ).

The date and GPS locations of any verifiable sightings and signs of medium and large mammals were recorded during each expedition. Analyses of photographs from each camera trap survey were limited to those photographs taken from 12:01am the day after setting up a camera trap until 12:00 pm of day before camera trap stopped recording. To ensure independence of capture events for each camera trap, images of individuals of the same species were ignored if captured within one hour of a previous sighting (O’Brien et al. 2003). For each photograph we recorded the site, date, time, and species. We excluded sightings of birds, small $(<1 \mathrm{~kg})$ mammals, domestic animals, people, and any unidentifiable images. The total number of capture events (n) per species was tallied and their percentage contribution (spp \%) to the total number of photographs was calculated. The capture frequency $(\mathrm{CF})$ for each species was calculated as the number of capture events (n) per 100 camera-trapping days (Tobler et al. 2008).

\section{Results}

\section{Mammal list for Angola}

An updated species checklist of 275 species of Angolan mammals is presented in Suppl. material 1, comprising 245 species records obtained from GBIF and an additional 30 species added from the literature and recent surveys (additional records marked in bold in Suppl. material 1). The list excludes commensal and domesticated species. Of this total, nine bat species were added to the revised GBIF list by Monadjem et al. (2010a), four rodent species were added by Monadjem et al. (2015), and additional bat, rodent and shrew species were added by the current survey (see paragraph below). 


\section{New small mammal capture data from Okavango Basin}

We collected 68 specimens of 24 species of small mammals (three shrew, ten rodent, and 11 bat species; Table 1). Of these species, one bat (Laephotis angolensis, the Angolan long-eared bat) and one rodent (Otomys anchietae, the Angolan vlei rat) are Angolan endemics (Table 1). One bat (Pipistrellus rusticus, rusty pipistrelle), two rodent species (Mus setzeri Setzer's mouse and Zelotomys woosnami Woosnam's broad-faced mouse) and one shrew (Suncus varilla, lesser dwarf shrew) were recorded for the first time in Angola, all listed as Least Concern, by the IUCN Red List. Two of the bat species were listed as Data Deficient (Plerotes anchietae, Anchieta's broad-faced fruit bat and Angolan long-eared bat) and one is classified as Near Threatened (Epomophorus angolensis, Angolan epauletted fruit bat), while one was not assessed.

There was a very marked difference in bat activity between March 2016 (which was characterised by heavy rainfall), when only 13 bats were caught, and October/ November 2016 (less frequent rainfall) when 151 bats were collected, in spite of very similar trap/net effort and six nights sampled for both periods. Captures in late 2016 were dominated by Pipistellus rusticus, Neoromicia capensis, and N. zuluensis.

\section{New acoustic data from the Okavango Basin}

From manual identification of zero-crossing calls, we identified a total of 29 putative species of insectivorous bats (Tables 2, Suppl. material 2).

\section{Diversity and importance of small mammals in Angola and the Okavango source lakes region}

The current capture survey adds one bat species, two rodent species and one shrew species to the country lists above, bringing to 67 and 87 the total number of Angolan bat and rodent species. From our current survey, we recorded 13 non-volant small mammals from the upper Okavango catchment of Angola, and some 33 species of bats, based on the estimate of insectivorous species from acoustic data (29 species; see above) combined with one rare species (Mimetillus thomasi, Thomas's flat headed bat), for which we have no echolocation data, and three additional species of fruit bats captured with mist nets/harp-traps (Table 1).

\section{Camera trap data from the Okavango source lakes region}

A total of 35 species of medium-large mammals, from 17 families were recorded in 2016 through opportunistic sightings and two formal camera-trapping surveys (Table 3). Ten species were recorded by both camera surveys and opportunistic sightings (common 
Table I. List of small mammal species collected in the central region of Angola in 2013 (four specimens) and 2016 (64 specimens) and deposited in the Durban Natural Science Museum. All specimens were checked by PJT based on cleaned skulls and skins in ethanol.

\begin{tabular}{|c|c|c|c|}
\hline Species & Common name & IUCN status & Localities recorded \\
\hline \multicolumn{4}{|l|}{ Order Chiroptera } \\
\hline Plerotes anchietae & Anchieta's Broad-Faced Fruit Bat & Data Deficient & Cuanavale Source \\
\hline Epomophorus angolensis & Angolan Epauletted Fruit Bat & Near Threatened & Cuchi Gorge \\
\hline Epomops dobsonii & Dobson's Epauletted Fruit Bat & Least Concern & Sambojana, Saliakembo \\
\hline Hypsugo anchietae & Anchieta's pipistrelle & Least Concern & $13 \mathrm{~km}$ north of Chett \\
\hline *Pipistrellus rusticus & Rusty Pipistrelle & Least Concern & $\begin{array}{c}\text { Cuito Source, Sambojana, } \\
\text { Cuanavale Source, Saliakembo }\end{array}$ \\
\hline Neoromicia zuluensis & Zulu Pipistrelle & Least Concern & $\begin{array}{l}\text { Cuanavale Source, } \\
\text { Saliakembo Source }\end{array}$ \\
\hline Neoromicia capensis & Cape Serotine & Least Concern & $\begin{array}{l}\text { Cuanavale Source, } \\
\text { Saliakembo Source }\end{array}$ \\
\hline${ }^{* *}$ Laephotis angolensis & Angolan Long-Eared Bat & Data Deficient & $\begin{array}{l}\text { Cuanavale Source, Sambojana, } \\
\text { Saliakembo Source }\end{array}$ \\
\hline Scotophilus leucogaster & White-bellied House Bat & Least Concern & Saliakembo Source \\
\hline Mimetillus thomasi & Thomas's flat-headed bat & Not assessed & $\begin{array}{l}\text { Cuanavale Source, } \\
\text { Saliakembo Source }\end{array}$ \\
\hline Chaerephon nigeriae & Nigerian Free-Tailed Bat & Least Concern & Cuanavale Source \\
\hline \multicolumn{4}{|l|}{ Order Soricomorpha } \\
\hline Crocidura fuscomurina & Bicolored musk shrew & Least Concern & Mupapa Falls \\
\hline Crocidura hirta & Reddish-Grey Musk Shrew & Least Concern & $\begin{array}{l}\text { Cuanavale Source, } \\
\text { Saliakembo Source }\end{array}$ \\
\hline * Suncus varilla & Lesser Dwarf Shrew & Least Concern & En route to Sambojana \\
\hline \multicolumn{4}{|l|}{ Order Rodentia } \\
\hline${ }^{* *}$ Otomys anchietae & Angolan Vlei Rat & Least Concern & Cuito Source \\
\hline Rhabdomys cf. dilectus & Striped Mouse & Least Concern & Cuanavale Source \\
\hline Mastomys natalensis & Multimammate mouse & Least Concern & Cuanavale Source Lake \\
\hline${ }^{*}$ Mus setzeri & Setzer's Mouse & Least Concern & $\begin{array}{l}\text { Cuanavale Source, Cuito Source } \\
\text { Cunde Falls }\end{array}$ \\
\hline Lemniscomus griselda & Single-Striped Mouse & Least Concern & $25 \mathrm{~km}$ west of Menongue \\
\hline *Zelotomys woosnami & Woosnam's Broad-Faced Mouse & Least Concern & Cuito Source \\
\hline Gerbilliscus leucogaster & Lowveld Gerbil & Least Concern & Cuanavale Source, Cunde Falls \\
\hline Graphiurus kelleni & Dormouse & Least Concern & Cuito Source \\
\hline Saccostomus campestris & Pouched mouse & Least Concern & $\begin{array}{c}\text { Cuanavale Source, Cuito Source, } \\
\text { Sambojana }\end{array}$ \\
\hline Steatomys krebsii & Fat Mouse & Least Concern & $\begin{array}{c}\text { Cuanavale Source, Cuito Source, } \\
\text { Mupapa Falls }\end{array}$ \\
\hline
\end{tabular}

* New record for Angola ** Angola endemic.

duiker, large-spotted genet, honey badger, side-striped jackal, serval, spotted hyena, porcupine, scrub hare, and vervet monkey; see Table 3 for scientific names). Eleven species were recorded by the camera traps only (greater bushbaby, tree squirrel, springhare, aardwolf, caracal, African wild cat, lion, aardvark, blue duiker and steenbok). Five species were only detected opportunistically during expeditions (African elephant, oribi, roan, lechwe and sitatunga). 
Common duikers and large-spotted genets were the most frequently photographed species in both camera surveys (Table 3). Interestingly, leopards were only recorded in the second camera survey and not the first, but a total of four per 100 days of sampling would likely yield a single leopard photographic event, higher than any other carnivore recorded in our study (Table 3). Other species which stood out during one or both of the camera surveys were vervet monkeys, side-striped jackals, bushpigs, silver-backed duiker and blue duiker. All other species, although detected during the course of the study, were recorded in less than one per 100 days of sampling (Table 3). Unfortunately, $15 \%$ of the photographic events in the first camera survey were unidentifiable due mostly to poor placement of cameras (Table 3 ).

\section{Discussion}

\section{Surveys of Okavango source lakes}

Based on both acoustic and trapping surveys, at least 46 species of small mammals occur in the upper Okavango catchment region, including several rare and endemic species. This diversity compares favourably with studies reviewing the diversity of terrestrial small mammals (Taylor et al. 2015) and bats (Schoeman et al. 2013; Taylor et al. 2013; Cooper-Bohannon 2016; Herkt et al. 2016) in African highlands generally. However, the estimate of terrestrial small mammal richness is probably grossly under-estimated as a GBIF search of central Angola yielded 42 species, compared with our list of 13 species of shrews and rodents based on captures. Many of the small mammals recorded in our survey such as shrews, Anchieta's vlei rat and fruit bats are habitat specialists which would be adversely affected by deterioration of wetlands due to anthropogenic effects such as extensive fires, tree clearing, wetland drainage and overgrazing, typical in the Miombo woodlands (Syampungani et al. 2009; Jew et al. 2016). Fruit bats provide valuable ecosystem services through seed dispersal and pollination, Anchieta's broad-faced fruit bat possesses whiskers which are thought to be involved in pollination (Monadjem et al. 2010). Bats of the genera Eidolon, Epomophorus, and Rousettus are known to pollinate baobab trees (Adansonia digitata) over much of Africa (Baum 1995).

\section{Mammal checklist}

\section{Afrosoricida}

This order is represented by two families in mainland Africa: Chrysochloridae (golden moles) and Potamogalidae (otter-shrews). Angola harbours just one species of golden mole, the Congo golden mole Huetia leucorhina (previously Calcochloris leucorhinus, see Asher et al. 2010). This group of subterranean fossorial mammals is therefore either poorly represented in Angola, or it has been greatly overlooked in the country. The species H. leucorbina is classified as Data Deficient and is known from just 10 scattered 


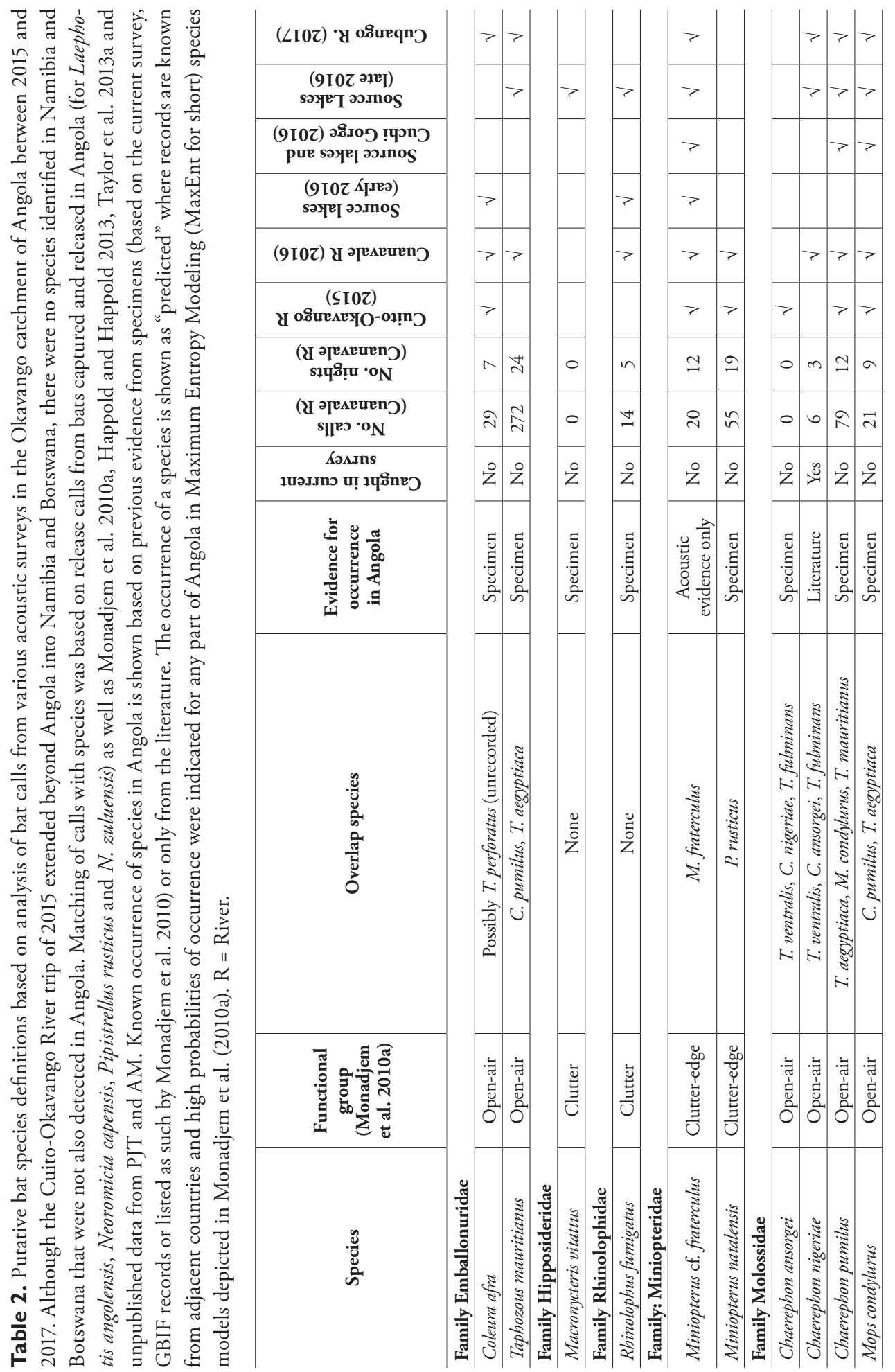




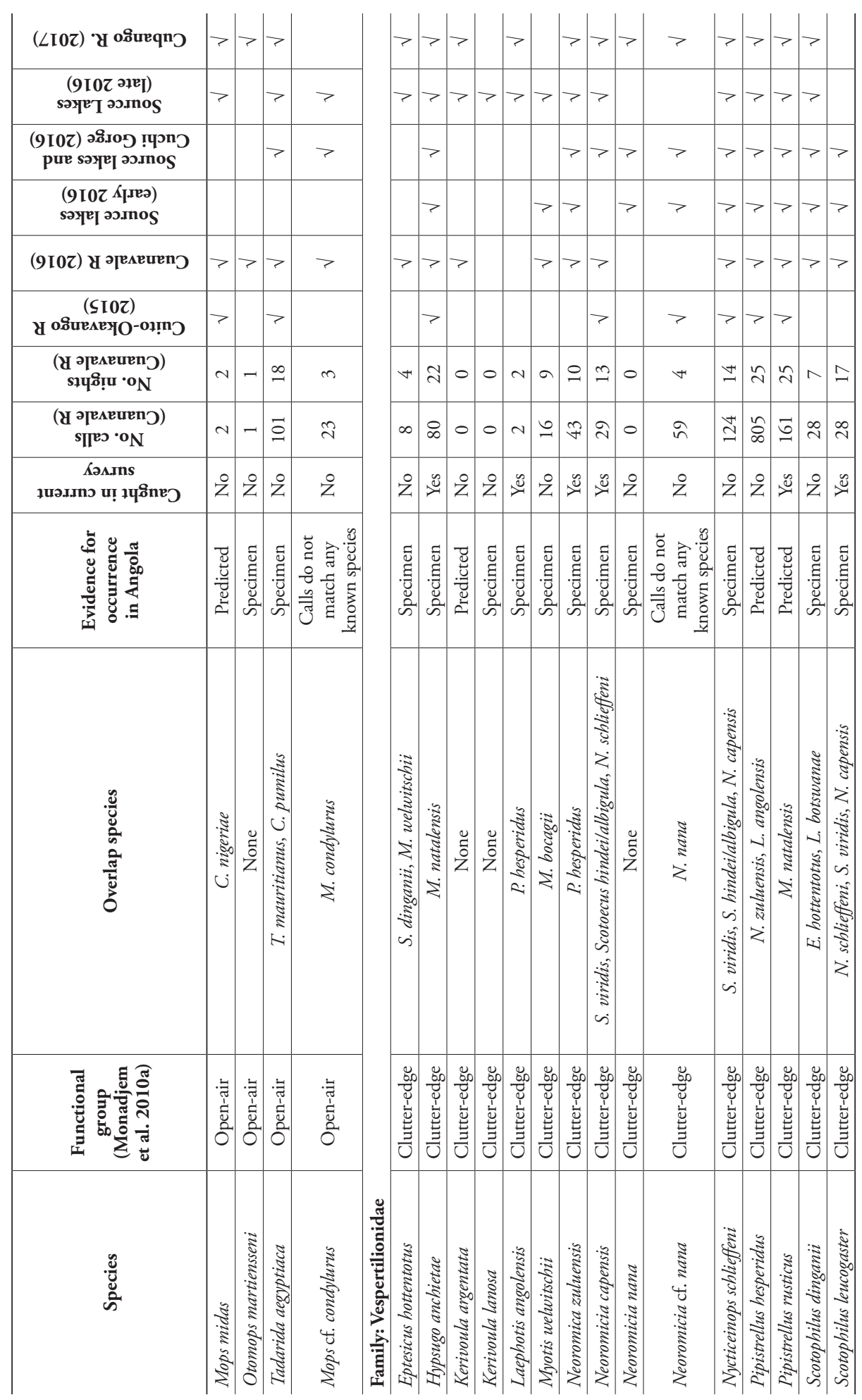


Table 3. All medium-large mammal species detected opportunistically (see methods) and during two formal camera-trapping surveys of the south-eastern highlands of Angola in 2016. Where applicable, the total number of photographic events per species (n), their percentage contribution (Spp. \%) to the total number of photographic events, and the capture frequency (CF) (number of events/100 camera days) is shown. $\mathrm{V}$ = verified opportunistic sighting, $\mathrm{C} 1$ = camera trap survey $1, \mathrm{C} 2$ = camera trap survey 2. If a species was recorded in both camera-trapping surveys, the values for both surveys are separated by a backslash (i.e., C1/C2).

\begin{tabular}{|c|c|c|c|c|c|c|c|c|}
\hline Family & Species & Common name & $\mathbf{V}$ & $\mathrm{C1}$ & $\mathrm{C} 2$ & $\mathbf{n}$ & Spp. $\%$ & $\mathrm{CF}$ \\
\hline Galagidae & Otolemur crassicaudatus & Greater bushbaby & & $\sqrt{ }$ & & 3 & 2.5 & 0.3 \\
\hline Cercopithecidae & Chlorocebus cynosuros & Vervet monkey & $\sqrt{ }$ & $\sqrt{ }$ & $\sqrt{ }$ & $10 / 3$ & $8.5 / 0.6$ & $1.1 / 0.2$ \\
\hline Leporidae & Lepus victoriae & Africa savanna hare & $\sqrt{ }$ & $\sqrt{ }$ & $\sqrt{ }$ & $8 / 7$ & $6.8 / 1.5$ & $0.9 / 0.5$ \\
\hline Sciuridae & Paraxerus cepapi & Tree squirrel & & $\sqrt{ }$ & & 1 & 0.9 & 0.1 \\
\hline Pedetidae & Pedetes capensis & Springhare & & & $\sqrt{ }$ & 11 & 2.3 & 0.8 \\
\hline Hystricidae & Hystrix africaeaustralis & Porcupine & $\sqrt{ }$ & $\sqrt{ }$ & $\sqrt{ }$ & $2 / 8$ & $1.7 / 1.7$ & $0.2 / 0.6$ \\
\hline Protelidae & Proteles cristatus & Aardwolf & & $\sqrt{ }$ & & 1 & 0.9 & 0.1 \\
\hline Hyaenidae & Crocuta crocuta & Spotted hyena & $\sqrt{ }$ & $\sqrt{ }$ & $\sqrt{ }$ & $2 / 6$ & $1.7 / 1.2$ & $0.2 / 0.4$ \\
\hline \multirow{6}{*}{ Felidae } & Acinonyx jubatus & Cheetah & & $\sqrt{ }$ & $\sqrt{ }$ & $3 / 1$ & $2.5 / 0.2$ & $0.3 / 0.1$ \\
\hline & Caracal caracal & Caracal & & & $\sqrt{ }$ & 3 & 0.6 & 0.2 \\
\hline & Felis lybica & African wildcat & & & $\sqrt{ }$ & 1 & 0.2 & 0.1 \\
\hline & Leptailurus serval & Serval & $\sqrt{ }$ & $\sqrt{ }$ & $\sqrt{ }$ & $1 / 1$ & $0.9 / 0.2$ & $0.1 / 0.1$ \\
\hline & Panthera leo & Lion & & & $\sqrt{ }$ & 1 & 0.2 & 0.1 \\
\hline & Panthera pardus & Leopard & $\sqrt{ }$ & & $\sqrt{ }$ & 48 & 10.0 & 3.6 \\
\hline \multirow{2}{*}{ Canidae } & Lycaon pictus & African wild dog & $\sqrt{ }$ & & $\sqrt{ }$ & 8 & 1.7 & 0.6 \\
\hline & Canis adustus & Side-striped jackal & $\sqrt{ }$ & $\sqrt{ }$ & $\sqrt{ }$ & $4 / 13$ & $3.4 / 2.7$ & $0.4 / 1.0$ \\
\hline \multirow{2}{*}{ Mustelidae } & Mellivora capensis & Honey badger & $\sqrt{ }$ & $\sqrt{ }$ & $\sqrt{ }$ & $1 / 4$ & $0.9 / 0.8$ & $0.1 / 0.3$ \\
\hline & Ictonyx striatus & Striped polecat (Zorilla) & $\sqrt{ }$ & & $\sqrt{ }$ & 1 & 0.2 & 0.1 \\
\hline \multirow{2}{*}{ Viverridae } & Civettictis civetta & African civet & $\sqrt{ }$ & $\sqrt{ }$ & & 3 & 2.5 & 0.3 \\
\hline & Genetta maculata & Large-spotted genet & $\sqrt{ }$ & $\sqrt{ }$ & $\sqrt{ }$ & $25 / 3$ & $21.2 / 0.6$ & $2.6 / 0.2$ \\
\hline \multirow{3}{*}{ Herpestidae } & Atilax paludinosus & Marsh mongoose & $\sqrt{ }$ & & $\sqrt{ }$ & 1 & 0.2 & 0.1 \\
\hline & Ichneumia albicauda & White-tailed mongoose & & $\sqrt{ }$ & $\sqrt{ }$ & $2 / 9$ & $1.7 / 1.9$ & $0.2 / 0.7$ \\
\hline & Mungos mungo & Banded mongoose & & $\sqrt{ }$ & & 1 & 0.9 & 0.1 \\
\hline Orycteropodidae & Orycteropus afer & Aardvark & & & $\sqrt{ }$ & 4 & 0.8 & 0.3 \\
\hline Elephantidae & Loxodonta africana & African elephant & $\sqrt{ }$ & & & - & - & - \\
\hline \multirow{2}{*}{ Suidae } & Potamochoerus porcus & Bushpig & $\sqrt{ }$ & $\sqrt{ }$ & $\sqrt{ }$ & $1 / 24$ & $0.9 / 5.0$ & $0.1 / 1.8$ \\
\hline & Phacochoerus africanus & Warthog & $\sqrt{ }$ & & $\sqrt{ }$ & 5 & 1.0 & 0.4 \\
\hline \multirow{8}{*}{ Bovidae } & Cephalophus silvicultor & Silver-backed duiker & & $\sqrt{ }$ & $\sqrt{ }$ & $5 / 14$ & $4.2 / 2.9$ & $0.5 / 1.0$ \\
\hline & Philantomba monticola & Blue duiker & & $\sqrt{ }$ & $\sqrt{ }$ & $4 / 19$ & $3.4 / 3.9$ & $0.4 / 1.4$ \\
\hline & Sylvicapra grimmia & Common duiker & $\sqrt{ }$ & $\sqrt{ }$ & $\sqrt{ }$ & $23 / 285$ & $19.5 / 59.1$ & $2.5 / 21.1$ \\
\hline & Ourebia ourebi & Oribi & $\sqrt{ }$ & & & - & - & - \\
\hline & Raphicerus campestris & Steenbok & & & $\sqrt{ }$ & 2 & 0.4 & 0.1 \\
\hline & Hippotragus equinus & Roan & $\sqrt{ }$ & & & - & - & - \\
\hline & Kobus leche & Lechwe & $\sqrt{ }$ & & & - & - & - \\
\hline & Tragelaphus spekii & Sitatunga & $\sqrt{ }$ & & & - & - & - \\
\hline Unidentifiable & Unidentifiable & Unidentifiable & & $\sqrt{ }$ & & 18 & 15.2 & - \\
\hline
\end{tabular}


locations including one from Angola where a series of seven specimens from the Field Museum of Natural History were collected by H. R. Heinrich in 1954-1955 from Canzele, $30 \mathrm{~km}$ west of Camabatela in central Angola. Otter-shrews are represented by just three species, all of them associated with tropical forests in Africa. Of these, the largest and most widely distributed Potamogale velox has been recorded from numerous localities in forested regions of northern Angola.

\section{Carnivora}

In addition to 37 species of Angolan carnivores in the GBIF database, reliable literature records (Kingdon and Hoffmann 2013a) add three species, including the Congo clawless otter Aonyx congicus and the African golden cat Profelis auratus from N Angola, and the black-footed cat Felis nigripes from extreme south-east Angola. The king genet Genetta poensis, the servaline genet $G$. servalina, the central African linsang Poiana richardsonii, the long-nosed mongoose Xenogale naso and the black-legged mongoose Bdeogale nigripes all have distributions apparently encompassing or bordering Cabinda but without any specific mention of their occurrence in Cabinda, Angola (Kingdon and Hoffmann 2013a) so we do not add them to the checklist.

This order is represented by seven terrestrial families in Africa: Canidae (dogs), Mustelidae (weasels, polecats and allies), Nandiniidae (palm civet), Felidae (cats), Viverridae (genets and civets), Hyaenidae (hyenas and aardwolf) and Herpestidae (mongooses). Five canid species have been recorded in Angola. However, only two species (African wild dog Lycaon pictus and side-striped jackal Canis adustus) were photographed and/or sighted in the Okavango catchment during our 2016 assessment. Nevertheless, the relatively frequent rate with which the wild dogs were photographed on the camera traps (capture frequency $=0.6$ ) is pleasing given their Red List Endangered status on the continent.

Eight felid species occur in Angola of which six (all except $P$. auratus and F. nigripes) were recorded during our 2016 camera trapping, suggesting that these species may have relatively cosmopolitan distributions across the country. However, our field data indicates that the largest of these obligate carnivores (the lion Panthera leo) occurs at much lower densities than the other felids. The lion is often one of the first species to be lost from the large carnivore guild when prey becomes limiting and/or conflict with humans escalates (sensu the effects of war). Thus, their presence in the south-east of Angola (albeit patchy) suggests some post-civil war recolonization. Interestingly, leopards $P$. pardus were the most frequently encountered felid during the 2016 camera trapping (capture frequency $=3.6$ ) supporting the notion that leopards are adaptable generalists.

Two hyena species and the aardwolf Proteles cristatus have been recorded in Angola. However, only the aardwolf and the spotted hyena Crocuta crocuta were photographed in our 2016 assessment. The latter finding is somewhat unsurprising given that brown hyena Parahyaena brunnea density is known to be negatively correlated with that of spotted hyenas (Mills 2015). 
The Herpestidae family is presented by 12 Angolan species, with several of these species occurring throughout much of sub-Saharan Africa. Three species of the mongoose family were formally recorded in the Okavango catchment survey of 2016, the marsh mongoose, Atilax paludinosus was recorded from a visual and camera survey, with banded mongoose, Mungos mungo and white-tailed mongoose Ichneumia albicaudata just recorded by camera surveys. The banded mongoose occurs in a broad range of habitats, with extensive range throughout Angola (Gilchrist and Do Linh San 2016). Selous's Mongoose, Paracynictus selousi occurs in savanna and woodland in central and southern parts of Angola (Stuart and Stuart 2013a). The black-legged mongoose, Bdeogale nigripes occurs in far north-west Angola (van Rompaey and Colyn 2013a). Yellow mongooses Cynictis penicillata occur marginally in southern Angola (Taylor 2013a). The highly social meerkat, Suricata suricatta, is endemic to the more arid open regions of western parts of southern Africa, and has a marginal intrusion in to SW Angola (Macdonald 2013). The dwarf mongoose (Helogale parvula, and a subspecies $H$. parvula mimetra (sometime treated as valid species $H$. mimetra) are reported to occur in Angola (Creel 2013), with $H$. parvula reported to occur in open woodlands, thickets and often associated with termite mounds etc., allowing for suitable dens (Creel 2013). Creel (2013) also indicates that there is a subspecies $H$. p. varia that occurs in north-east Angola.

Three species of Herpestes occur in Angola, the Egyptian mongoose, H. ichneumon (Do Linh San et al. 2016), the common slender mongoose H. sanguineus (Hoffmann and Taylor 2013), and the Kaokoveld slender mongoose, H. flavescens from SW Angola including Benguela Province (Taylor 2013c). The taxonomic history of $H$. flavescens is very confusing. It has been included as a chestnut-coloured race of different species included in either $H$. pulverulentus or $H$. ochraceus but these two last-mentioned species are now considered to have much more restricted distributions in South Africa and $S$ Namibia and Somalia and Ethiopia respectively. Crawford-Cabral (1996) demonstrated that flavescens was conspecific with the blackish-coloured nigrata race from north-east Namibia, a view that we follow. A chestnut-coloured form from Caconda near Benguela in Angola, H. ansorgei Thomas \& Schwann, 1905 should be assigned to H. flavescens on colour and geographic grounds, and not to $H$. ochraceus as proposed by Taylor (2013b).

Ansorge's Crusimanse Crossarchus ansorgei is a cryptic Angolan Herpestidae species known from a single location from the proposed Angolan distribution collected in 1908 (Angelici and Do Lin San 2015 citing Crawford-Cabral 1989; Van Rompaey and Colyn 2013b).

Mustelidae. The Zorilla, Ictonyx striatus, ranges across a broad range of habitats of sub-Saharan Africa, and is common throughout its range, yet reported to be locally uncommon (Stuart and Stuart 2013b). Our upper Okavango catchment study of 2016 recorded this species by visual sightings and camera trap surveys. African clawless otters, Aonyx capensis, are medium sized otter species, and occur widely, associated with seasonal rivers, and can occur in fresh and marine water. The clawless otter is reported to have a distribution range in the central and southern parts of Angola (Somers and Nel 2013), yet was not recorded in the 2016 assessment. The spotted necked otter, Hydrictis maculicollis appears to be closely linked to permanent freshwater systems with 
abundant food resources (fish) and shoreline cover. Their continental distribution is considered to be wide. However, there is a paucity of information for this otter species in Angola (Reed-Smith et al. 2015). The ratel, Mellivora capensis, occurs across Africa in most habitat types, from deserts to forests. This species is reported to exist in low densities, and is often regarded to be rare throughout its range (Begg et al. 2013). This species was recorded in the Okavango catchment expedition through visual observation and camera trap survey. African striped weasels, Poecilogale albinucha, are thought to be uncommon and rare, throughout their extensive range in sub-Saharan Africa (Stuart and Stuart 2013c), and are delineated to occur in the northern parts of Angola.

Nandiniidae. The two-spotted Palm Civet, Nandinia binotata, are arboreal and found across the west and central African forest belt, likely to only be found in the North east of Angola (Gaubert 2013).

Viverridae. The African civet, Civettictis civetta, is distributed throughout sub-Saharan Africa, with suitable habitat from $29^{\circ} \mathrm{S}$ latitude extending north to south of $15^{\circ} \mathrm{N}$ latitude, and a commonly encountered carnivore (Ray 2013). This species was recorded from visual observation and through camera trap surveys in our upper Okavango catchment expedition. The Miombo genet, Genetta angolensis, originally known from three adult specimens, lost in a fire in 1978 (Crawford-Cabral 2013) has a broad distribution from Angola, Democratic Republic of Congo, Mozambique, Malawi, Zambia and Tanzania. This species is reported to be similar in size to the common genet, and occurs in "open miombo woodlands" and is reported to be locally common in some areas (e.g., the Luando Strict Nature Reserve (Central Angola) (Crawford-Cabral 2013, Gaubert et al. 2016). The common genet, Genetta genetta, is a widespread and locally common genet, and in its southern distribution range occur from central and south Angola through Botswana, Namibia, Zimbabwe and South Africa, replaced to the east by the large spotted genet (Delibes and Gaubert 2013). Genetta maculata, along with G. tigrina and G. pardina form part of the 'large spotted genet complex' (Gaubert and Dunham 2013). The species is very common and widespread with over 50 localities recorded by GBIF records. Based on camera trap images and visual sightings, $G$. maculata was present during the Okavango catchment expeditions in 2016. The servaline genet G. servalina is depicted as occurring in Cabinda by Van Rompaey and Colyn (2013c) but without any specimen or sighting records, its occurrence there is dubious albeit possible.

\section{Certartiodactyla}

This order is represented by five indigenous families in Africa and Angola: Suidae (pigs), Hippopotimidae (hippopotamuses), Tragulidae (chevrotains), Giraffidae (giraffes) and Bovidae (bovines and antelopes). Following the taxonomy of Kingdon and Hoffman (2013b), a total of 32 artiodactlys are recognised in Angola, of which 26 are bovids (Suppl. material 1). Following the taxonomy of Groves and Grubb (2011), the list would result in 35 Angolan Artiodactyla including 29 bovids. This increase of three bovid species is because these latter authors regard Lichtensteini's harbertebeest Alcelaphus lichtensteini as a separate species from the red hartebeest $A$. buselaphus; further- 
more, two species (a tropical forest Kabinda species and a southern savanna species) are recognised each within the African buffalo (Syncerus nanus and S. caffer respectively) and the bushbuck (Tragelaphus ornatus and T. phaleratus respectively) populations from Angola. The taxonomy of Groves and Grubb (2011) doubled the number of recognised African ungulate species. This species-splitting process would raise several local Angolan subspecies to species rank and result in name changes for several of the Angolan ungulates. It would make two bovid species endemic to Angola, the Angolan blue duiker Philantomba anchietae and the Angolan springbok Antidorcas angolensis. The klipsringer Oreotragus tyleri would become near-endemic to Angola, extending marginally to north-west Namibia. Some conservationists have opposed the taxonomy of Groves and Grubb (2011); for recent debates see: Gippoliti and Groves (2012), Heller et al. (2013), Zachos et al. (2013), Cotterill et al. (2014), Heller et al. (2014), Garnett and Christidis (2017), Cotterill et al. (2017), and Groves et al. (2017).

GBIF yielded 5,821 species-identified historical records of Artiodactyla dating back to 1889 , of which 5,438 were compiled by the IICT in Portugal, and 385 were preserved specimens, predominantly from the American Museum of Natural History and Field Museum of Natural History. These records provide valuable insights into the historical distribution of the larger ungulates, some of which have become extinct or almost extinct in the wild in Angola. For example, the GBIF database provides 13 georeferenced records of Lichtenstein's hartebeest from 13 localities throughout E Angola, whereas this species is now thought to be extinct in Angola (Gosling and Capellini 2013). The GBIF database contains 213 records (including 25 museum specimens dating back to 1925) of the blackfaced impala (Aepyceros melampus petersi) from 78 georeferenced localities throughout $S$ Angola whereas the status of the species in Angola is currently uncertain. It occurs at Iona National Park and possibly two other national parks (Fritz and Bourgarel 2013). The case of the three sable subspecies, the nominate form (Hippotragus niger niger), Kirk's sable ( $H$. niger kirkii) and the giant sable $H$. n. variani is also remarkable. All three subspecies were widespread in central, south-eastern, and eastern Angola (Figure 3) but are currently much more restricted. The giant sable came close to extinction during the Angola civil war and is currently known from just two reserves in central Angola, the Cangandalo National Park and the Luando Reserve (Figure 3) where its survival continues to be threatened by poaching and hybridization with roan antelope Hippotragus equinus (Vaz Pinto 2006, 2018; Estes 2013). In the case of Kirk's sable from eastern Angola, (Figure 3), there have been no observations for 40 years (Cabral and Veríssimo 2005). However the nominate race $(H$. n. niger) is still known to occur in the region between the Cuito and Cuando Rivers in southeastern Angola, including the Luengue-Luiana and Mavinga National Parks (Funston et al. 2017, Figure 3). However no sable were detected in the present camera trap survey or ad hoc observations conducted in the upper Okavango catchment.

A dubious record of the common reedbuck Redunca redunca from Calunga in SE Angola in the Los Angeles County Museum must be a misidentified $R$. arundinum since $R$. redunca is not known to occur anywhere near Angola (Kingdon and Hoffman 2013b).

As one of the most speciose certartiodactyl families in Africa, it is unsurprising that 26 bovid species occur in Angola. Only eight of these species were recorded during our 2016 


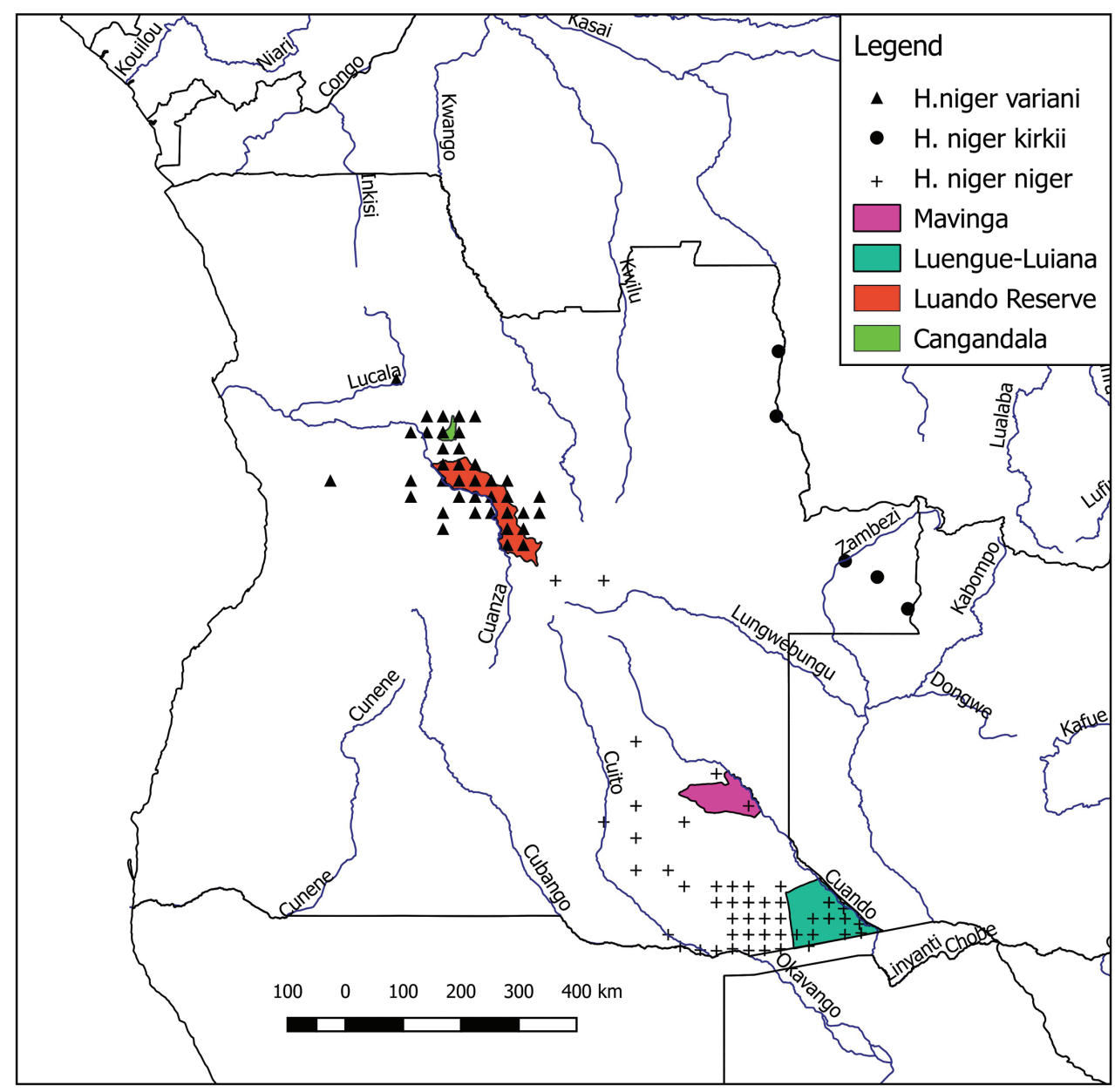

Figure 3. Historical distribution of the nominate sable subspecies (Hippotragus niger niger), Kirk's sable (H. niger kirkii) and the giant sable (H. niger variani) in Angola based on records of the Instituto de Investigação Científica Tropical (IICT) in Portugal (obtained via GBIF search). Protected areas where $H$. n. niger and $H$. n. variani currently known to occur are indicated in the legend. The subspecies $H$. $n$. kirkii from eastern Angola has not been recorded during the past 40 years.

survey in the south-east (Cephalophus silvicultor, Philantomba monticola, Sylvicapra grimmia, Ourebia ourebi, Raphicerus campestris, Hippotragus equinus, Kobus leche and Tragelaphus spekii). Anecdotal data from our camera trapping and discussions with local Angolans suggests that the bovids are likely the most targeted mammalian group when it comes to poaching for bushmeat that is routinely traded commercially in many parts of the country.

Three pig species have been recorded in Angola. The common warthog Phacochoerus africanus and the bushpig Potomochoerus larvatus have been collected/sighted from numerous localities across Angola. However, the red river hog Potomochoerus porcus is restricted to the forested northern regions of the country based on 12 GBIF records 
(seven museum specimens and five additional historical records from IICT). Although not formally recorded during our 2016 camera trapping survey, hippopotamuses Hippopotamus amphibius have been regularly recorded across Angola wherever suitable water and nocturnal grazing is available. Only one chevrotain species Hyemoschus aquaticus has been recorded in Angola and this species occurs in the forested north of the country. The giraffe Giraffa camelopardalis has been recorded at numerous localities in Angola but was not formally recorded in the upper Okavango catchment during our 2016 assessment. However, what may have been giraffe tracks/spoor were noted.

\section{Chiroptera}

The GBIF search alone reported 59 species of Angolan bats while Monadjem et al. (2010a) reported 64, seven of which were not included in the GBIF search. The current survey added one new Angolan species record based on captures (Pipistrellus rusticus) and three tentative species records based on acoustic identification (Kerivoula argentata, Mops midas, Pipistrellus hesperidus; Table 2). Happold and Happold (2013) added one species (Triaenops afer). Merging these three sources resulted in a combined list of 71 species (Suppl. material 1). Over 220 species of bats have been recorded in mainland Africa of which over 75\% occur in Sub-Saharan Africa (Happold and Happold 2013). Of these, 116 species occur in southern Africa defined by Monadjem et al. (2010a), a region which includes Angola. Within this region, the more diverse countries have bat species richness typically between 60-70 species (Monadjem et al. 2010b). For example, 67 species have been recorded in Mozambique, 65 species in Zambia, and 62 species each in Malawi and Zimbabwe (Monadjem et al. 2010b). Therefore, the current total of 71 species that we report for Angola in this study, is on the higher end of richness for the region, in spite of the fact that Angola remains one of the most poorly known southern African countries with respect to bats (and mammals in general). For example, during the course of just a few weeks of fieldwork we were able to add a new species of bat to the country list, as well as additional (possible) new records of a further three species, based on echolocation calls, which would bring the total up to 71 species (making it the most diverse country in the region). We suspect that there are numerous species of bat that still await discovery in Angola, and we further predict that a number of new (and possibly endemic) species will be eventually recorded from the western escarpment region that is high in bird endemism (Mills et al. 2011, 2013). To the best of our knowledge, no recent bat (or other small mammal) surveys have been conducted in any of the remaining Afromontane forests and adjacent grasslands along this escarpment, and this must remain a critical zone for future surveys.

Two other regions are likely to be fruitful survey locations for bats. One is Kabinda which is on the northern side of the Congo River; this river forms a substantial barrier for African mammals resulting in it forming the southern limit for many species. To the best of our knowledge, Cabinda has not been surveyed specifically for bats before. We suspect that a large number of tropical rainforest species (e.g., Myopterus whitleyi, Mops annulus, Mops thersites and Nycteris grandis) will be shown to occur in Cabinda. The second is the extreme south-western arid zone on the Namibian border (part of 
which is included in Iona National Park). This region has also not been the focus of dedicated bat surveys, but may harbour arid zone specialist species (e.g., Sauromys petrophilus and Rhinolophus denti) that have not yet been recorded from Angola. We suspect that these three regions (western escarpment, south-western arid zone and Kabinda) will also harbour new country records of other mammal groups, and therefore encourage mammalogists to specifically target these areas.

One reason for this high bat diversity is the considerable range in habitats from lowland desert to high altitude Afromontane forest, and from open grassland to tropical rainforest. Despite the high diversity, no bat species are endemic to Angola. This is rather surprising considering the large number of endemic birds and reptiles (Mills et al. 2011). We suspect that future research will uncover endemic bat species to Angola, most probably along the western escarpment, and particularly on isolated mountain tops coated in forest. By way of example, Rhinolophus eloquens has been collected from Jau, Huila Province, a location that is over $2,000 \mathrm{~km}$ away from the closest records in the east of the Democratic Republic of Congo (DRC) and Rwanda. These specimens from the American Museum of Natural History are worth re-examining as we suspect that this may refer to a new species within the $R$. eloquens/ $R$. hildebrandtii group.

\section{Hyracoidea}

Four species of hyraxes are confirmed in Angola including two species of tree hyraxes (Kingdon et al. 2013a). A large number of records of the southern tree hyrax D. arboreus in the GBIF database come from 36 georeferenced localities in north-east Angola. The western tree hyrax $D$. dorsalis is known only from Cabinda in Angola (Shulz and Roberts 2013) and is vouched for by two specimens from the collection of the Royal Belgian Institute of Natural Sciences.

\section{Lagomorpha}

Only one lagomorph species (Lepus victoriae, African savanna hare) is known from Angola. GBIF records assigned to L. capensis, L. saxatilis and Poelagus marjorita must be mis-identifications as there is no valid modern records or voucher specimens for the occurrence of these species in Angola.

\section{Macroscelididae}

Only two species of sengis or elephant shrews are known to occur in Angola, Elephantulus brachyrhynchus and E. intufi (Suppl. material 1). Based on proximity to the border, Macroscelides proboscideus and Elephantulus rupestris may eventually be shown to occur in south-west Angola.

\section{Erinaceomorpha}

Only one widespread species in known, the southern African hedgehog, Atelerix frontalis. 


\section{Perissodactyla}

Three native species can be confirmed for Angola (Suppl. material 1). This order is represented by two families in Africa: Equidae (zebras) and Rhinocerotidae (rhinoceroses). Two zebra species can be confirmed to occur in Angola. The threatened Hartman's zebra Equus zebra hartmannae is known from Iona National Park while the plain's zebra E. quagga is more widely distributed across the country. A single Grevy's zebra E. grevyi specimen housed by UCM is from an unknown collector and the locality is simply given as Angola and is likely misidentified since the species is known only from Kenya and Ethiopia (Williams 2013). Only the black rhinoceros Diceros bicornis has been recorded in Angola and they have all but been extirpated from the country due to the civil war. No zebras or rhinoceroses were recorded during our 2016 camera trapping assessment.

\section{Pholidota}

Four species of pangolin are present in Africa, of which two have been confirmed within the borders of Angola (the ground pangolin Smutsia temmincki and the tree pangolin Phataginus tricuspid (Hill and Carter 1941; Kingdon and Hoffman 2013b) and two (Smutisa gigantea and Phataginus tetradactyla) may possibly occur in Cabinda (the Congo River is the southern limit for both these species); this makes Angola possibly the only country on the continent where all pangolin species probably occur.

\section{Primates}

After correcting for taxonomic changes, the GBIF database listed 17 species of primates occurring in Angola. Based on species distributions in Butynski et al. (2013), two of these GBIF records could not be verified. Although three un-dated specimens from the Royal Belgian Institute of Natural Sciences from Angola (no specific locality) were labelled as the grey-cheeked mangabey Lophocebus albigena, according to Butynski et al. (2013) the species occurs only north of Cabinda. While it could conceivably occur in Cabinda, until we have clear evidence, we regard the Angolan GBIF records of L. aligena as dubious. Likewise, although the Red-capped Mangabey Cercocebus torquatus is not documented as occurring in Angola by Ehardt (2013), two undated GBIF specimens from Cabinda in the Royal Belgian Institute of Natural Sciences collected by Serge M. Frechkop are labelled as C. torquata. Although the species is known to occur near to the Cabinda border, for the moment we treat this record as uncertain. Although the Kinda baboon Papio kindae from Angola was included as a synonym of the yellow baboon P. cyanocephalus by Butynski et al. (2013), it was shown to be distinct by Mittermeier et al. (2013). Therefore P. kindae and not P. cyanocephalus is found in Angola. One species not included in the GBIF database but validated by Goossens et al. (2002) and Butynski et al. (2013) as occurring in Cabinda, is the robust chimpanzee Pan troglodytes. Considering the above, we consider there to be 16 species of primates occurring in Angola. 
Cercopithecidae. The red-tailed monkey Chlorocebus ascanius (synonym Cercopithecus ascanius) occurs through most of central and north Angola into DRC and other countries. With a highly fragmented distribution, three subspecies are considered to occur in parts of Angola, C. a. katangae, C. a. atrinasus, and C. a. ascanius (Oates et al. 2008a). Chlorocebus ascanius atrinasus is reportedly found in northwest Lunda district of northeast Angola, and known from nine specimens (Oates et al. 2008b). GBIF records account for one 1925 Angolan specimen of $C$. ascanius in the American Museum of Natural History collected by Lang, and four specimens from the Field Museum collected in 1954 by G. H. Heinrich from Canzele, $30 \mathrm{~km}$ west of Camabatela. The range of the moustached monkey Cercopithecus cephus extends from Cameroon southwards into parts of far north west of Angola (likely Cabinda province) (Oates et al. 2008c). The gentle monkey, or blue monkey Cercopithecus mitis has great variation with disputed taxonomy but the nominate subspecies C. m. mitis is generally considered to be endemic to Angola (Lawes et al. 2013). The De Brazza's Guenon Cercopithecus neglectus is found in NE Angola associated with riverine forest habitats, common in many parts of its range (Struhsaker et al. 2008). The Malbrouck monkey Chlorocebus cynosuros is part of the $C$. aethiops (vervet) group but was elevated to full species by Groves (2001). Chlorocebus cynosuros extends throughout Angola, Zambia and parts of the DRC (Sarmiento 2013). A total of 25 GBIF records from six widely separated localities in west and central Angola document its widespread presence within the country.

The Angola colobus, Colobus angolensis, is considered to be endemic to equatorial Africa. The Sclater's Angola colobus, C. a. angolensis occur throughout the north-east part of Angola, with populations restricted to forest fragments (Bocian and Anderson 2013).

The southern Talapoin monkey Miopithecus talapoin, or Angolan Talapoin monkey is regarded as endemic to Northern Angola and south-west DRC.

The Kinda baboon occurs in central and northern parts of Angola (north of the Cunene river) ranging eastwards through DRC, Zambia. The preferred habitat of this species is reported to be Miombo (Brachystegia) woodland in the fire-climax stage (Kingdon 2016). The Chacma baboon Papio ursinus, is sympatric in Angola in some part of the range of Papio kindae, with the Chacma considered endemic to southern Africa. The species is considered to have three subspecies, of which two inhabits Angola: $P$. $u$. ruacana ranging into south and central Angola from its Namibian distribution and the $P$. u. griseipes ranging through Zimbabwe, Botswana, and Mozambique with a south eastern intrusion to Angola (Cowlishaw 2013). The chacma baboon occurs in a broad range of habitats within Angola (Hoffman and Hilton-Taylor 2008).

The southern lesser galago Galago moholi, ranges broadly across southern Afri$\mathrm{ca}$, Angola in the North-western extension of their range, reportedly being from the subspecies $G$. $m$. bradfieldi that occur in north Namibia and south central Angola through to southern DRC and then Zambia and Tanzania, south into northern South Africa (likely the G. m. moholi). The southern lesser galago prefers semi-arid woodland and savanna habitats (Pullen and Bearder 2013). The Demidoff's Dwarf Galago, Galagoides demidoff, also referred to $G$. demidovii, are recorded in the northern parts 
of Angola extending northwards and north-eastwards into the DRC Rainforest and Afromontane-Afroalpine forests zones (Bearder 2016). The large eared greater Galago, Otolemur crassicaudatus, (synonym Galago crassicaudatus) is found throughout most of southern Africa, ranging from Angola in the west, to Tanzania in the east, extend south into KwaZulu-Natal, South Africa. The proposed subspecies, the Miombo silver Galago Otolemur c. monteiri (or often elevated to species level O. monteiri) are found widely across the range in Angola (Bearder and Svoboda 2013). We photographed what we believe was Otolemur c. monteiri during one of the camera trap surveys in the Okavango catchment expedition in 2016.

The western Gorilla Gorilla gorilla, extends only into the Cabinda province of Angola.

The potto, Perodicticus potto, is considered to have several subspecies and even groups that can be elevated to species designation. The potto, $P$. potto edwardsi occurs in the north-east of Angola and in Cabina, occurring in a range of habitats (Pimley and Bearder 2013). Two undated specimens from Cabinda are located in the Royal Museum of Central Africa.

\section{Proboscidea}

There are two elephant species in Africa, Loxodonta africana and L. cyclotis and both occur in Angola (Kingdon et al. 2013a). Despite being the largest, and presumably most conspicuous mammal, records of elephant presence in Angola have declined substantially post-civil war. Their current distribution appears to be restricted to the northern parts of the country. However, elephant signs (dung and tracks but not photographs) were recorded during our 2016 survey in the Okavango catchment.

\section{Rodentia}

The 77 Angolan rodent species identified by the GBIF search provided a close match to the 78 Angolan rodent species recorded by Monadjem et al. (2015). Of the 77 species recorded by GBIF, four species were deleted from the final checklist as they could not be validated due to imprecise locality information and/or un-corroborated identifications which were not supported by other studies: the squirrel, Heliosciurus rufobrachium, the molerat Fukomys damarensis, the cane rat Thryonomys gregorianus and the climbing mouse, Dendromus messorius. An additional seven species were added based on validated species records from Happold (2013) or Monadjem et al. (2015): the squirrels, Funisciurus lemniscatus and Anomalurus beecrofti (Happold 2013), the dassie rat Petromus typicus, the long-eared mouse Malacothrix typica, the striped mouse Rhabdomys bechuanae, the giant rat Cricetomys emini, and the climbing mouse D. leucostomus (Monadjem et al. 2015). Two new species were added by the current survey of the Angolan Highlands: Setzer's mouse Mus setzeri and Woosnam's broad-headed mouse Zelotomys woosnami. This brings the final total of Angolan rodent species to 82 . As indicated below, several additional rodent species are known to occur on or close to the borders of Angola and will probably be shown to occur there in the future. 
Sciuridae. Thomas's rope squirrel Funisciurus anerythrus has been recorded at the border of Kabinda and could possibly occur there (Monadjem et al. 2015). The ribboned rope squirrel F. lemniscatus was recorded from Kabinda by Happold (2013) although not reported there by Monadjem et al. (2015). The red-legged sun squirrel Heliosciurus rufobrachium is not known to occur south of the Congo River but a GBIF record from "Raca Camele, north of Quionlungo" was attributed to a specimen from Yale Peabody Museum identified by A. Heinrich. We flagged this as a dubious record. The isolated population of the forest giant squirrel Protoxerus stangeri in northern Angola is treated as an endemic subspecies P. s. loandae (Happold 2013).

Gliridae. A high diversity of five species of dormice has been recorded in Angola.

Muridae. Muridae comprises by far the largest family of rodents and 42 indigenous murid species occur in Angola. The species list from the GBIF database corresponded closely with that of Monadjem et al. (2015). Our current trapping survey of the Okavango source lakes region added two murid rodent species to the list for Angola, Mus setzeri and Zelotomys woosnami (Table 1). As both of these rodents are associated with sandy soils in arid savannas it was surprising to record them from mesic miombo woodlands in the Angolan highlands. However, the rivers and source lakes of the upper Okavango catchment are bordered by sandy habitats that form obvious corridors for the dispersal of these species from the lower catchments of the Okavango Basin where they have hitherto been recorded in Botswana and Namibia. Given that two murid species were added to the country after just two weeks of survey effort in a limited area, it is highly likely that more species of murid rodents will be shown to occur in Angola by future collecting. For example tropical species such as Deomys ferrugineus, Lophuromys ansorgei, Hybomys univitattus, Hylomyscus aeta, H. anselli, Mylomys dybowski, Praomys petteri and Stochomys longicaudatus occur close to the border of Kabinda or north Angola. On the other hand, species from arid savannas associated with the Okavanga River in Botswana and Namibia, such as Dasymys cabrali, may also be found to occur in the upper Okavanga catchments. Although the desert pygmy mouse Mus indutus was shown to occur in south-east Angola by Happold (2013), identification of this species is difficult and no molecular sequences are available of this species from Angola (Lamb et al. 2014, Monadjem et al. 2015). Hence, this species is included in the checklist as a dubious record. Another semi-arid habitat murid species that extends into extreme south-west Angola is Rhabdomys bechuanae (Du Toit et al. 2012).

Nesomyidae. The presence of Emin's giant pouched rat Cricetomys emini from Kabinda is vouched by Musser and Carleton (2005) and Monadjem et al. (2015) but the species does not appear to occur as widely in north Angola as indicated in Happold (2013). The banana African climbing mouse Dendromus messorius was recorded by three specimens from the Field Museum from Dundo in the extreme north-east Angola collected by A. Barros Machado in 1948, but there are no known records close to this (Monadjem et al. 2015). We suspect this is a misidentification, and it is interesting that Hayman (1963) commented on a series of five Dendromus from the Dundo Museum as follows: "This unstriped Dendromys of the Lubda District appears to represent ansorgei rather than messorius Thomas of the Cameroons, under which name Sanborn (1952) 
listed a series from the Dundo region examined by him". Since ansorgei is a synonym of mystacalis, it seems very likely that specimens from Dundo refer to the chestnut African climbing mouse $D$. mystacalis. Vernay's African climbing mouse $D$. vernayi is endemic to the central highlands of Angola and only known from the type locality. The monotypic Dendroprionomys (velvet climbing mouse) is known only from the type locality Brazzaville which is close to Cabinda and may be shown to occur there. The long-eared mouse Malacothrix typica was not recorded in the GBIF database but is known from extreme south-west Angola (Hill and Carter 1941; De Graaff 1981).

Hystricidae. African brush-tailed porcupines Atherurus africanus have been recorded on the border region of Cabinda on both Congo and DRC sides, and undoubtedly this species occurs in Cabinda (Monadjem et al. 2015); however without material evidence we do not include it here. The common porcupine Hystrix africaeaustralis has been recorded throughout the country.

Petromuridae. Although not recorded in GBIF, several records of the dassie rat Petromus typicus are known from south-west Angola (Monadjem et al. 2015).

Thryonomyidae. The GBIF database contains records from three specimens labelled as Thryonomys gregorianus from mount Moco collected in 1954, but the closest known records of this species are from central DRC and west Zambia (Happold 2013; Monadjem et al. 2015). Given the difficulty in distinguishing this species from T. swinderianus, we treat this record as dubious.

Pedetidae. Only one widespread species is known to occur in Angola.

Anomaluridae. Although not listed in the GBIF database, both Happold (2013) and Monadjem et al. (2015) show Beecroft's scaly-tailed squirrel Anomalurus beecrofti occurring in Kabinda. Happold (2013) also indicates additional records from Angola south of the Congo River.

\section{Soricomorpha}

Our GBIF search revealed 13 species of shrews occurring in Angola, all from the genus Crocidura, but cross-checking against Hill and Carter (1943) and Happold and Happold (2013) resulted in two species being flagged as highly dubious, plus an additional two species known to occur in Angola (Hill and Carter 1943; Happold and Happold 2013), resulting in a final total of 13 species.

The lesser grey-brown shrew $C$. silacea and Dent's shrew $C$. denti are both included in the GBIF database but their known range is nowhere near Angola (Happold and Happold 2013). The C. denti record was an undated record from the Natural History Museum with no recorded locality. The $C$. silacea record was from the Field Museum of Natural History, collected in 1954 from near Quela in north Angola by G. H. Heinrich. Given its location many hundreds of kilometers from other known records, and difficulties in identification of this species, we believe this to be a misidentification and this record is regarded as highly dubious. The heather shrew $C$. erica and the blackish shrew $C$. nigricans are both endemic to Angola. Ansell's shrew C. ansellorum and the moonshine shrew $C$. luna have both been collected from the border region of Zambia and Angola, and probably occur in Angola. 
Both the greater dwarf shrew Suncus lixus and the climbing dwarf shrew Suncus megalura are known to occur in Angola (Happold and Happold 2013), hence were added to the final checklist (but were not captured in the GBIF database). Our field collections in the Okavango source lakes area in 2016 added an additional species for the country, the lesser dwarf shrew Suncus varilla (Table 1). The species has a sparse distribution and was previously known from sout-east DRC so its occurrence in central Angola is not surprising. Although Hill and Carter (1943) described a similar number of species (13) as here recognised (14), some of their names have become synonyms and their list corresponded to nine of the currently recognised species, representing a $44 \%$ increase in real diversity since 1943 .

\section{Tubulidentata}

The aardvark Orycteropus afer, is considered to be a common species in suitable habitats across its range which extends through most of sub-Saharan Africa (Taylor and Lehmann 2015), and is strongly associated with ant nests and termitaria. This species was recorded in the Okavango catchment expedition during our camera trap survey in 2016, and probably occurs widely in the country.

\section{Concluding remarks}

The current list of 275 species of Angolan mammals represents an increase of 52 species compared to the exhaustive survey of Hill and Carter (1941) that recorded 223 species. Throughout most of the twentieth century, Angola was largely neglected in terms of mammal research, particularly during the period of the civil war in the late twentieth century (1975-2002), but recent decades have seen renewed research efforts. For example, through the National Geographic Okavango Wilderness Project, acoustic, camera trap and trapping surveys carried out between 2015 and 2017 in the upper Okavango catchment, a previously neglected area, has added valuable new data on mammal occurrences. While estimates of bat species richness for the upper Okavango catchment based on combined acoustic and capture data from our study (33 species) correspond closely with predicted bat diversity for the region based on modelling studies (e.g., Herkt et al. 2016), our survey under-estimated non-volant small mammals species richness (13 species compared to 42 species predicted based on GBIF records for the central Angola plateau).

Rodrigues et al. (2015) identified four biogeographical subdivisions in Angola based mostly on ungulate distributions. In the north, the Zaire-Lunda-Cuanza region was mainly associated with Congolian forests. In the south, the Namibe and $\mathrm{Cu}$ nene-Cuando Cubango regions were mainly characterized by ungulates widespread in south-western and southern Africa. In between these regions, the Central Plateau region was mainly characterized by a few widespread ungulate species that are relatively common in dense miombo woodlands. These patterns were largely determined by a north-south gradient of decreasing humidity, from mesic tropical forests in the 
north to savannas and then more arid regions in the south. Patterns corresponding to this rainfall gradient are also evident in bats (Monadjem et al. 2010) and rodents (Monadjem et al. 2015). Angolan is known for a fairly high number of endemic or near-endemic species, particularly in the case of rodents and shrews, where our study identified one shrew and six rodents endemic to the central and western Angolan highlands. The western escarpment Afromontane forests of Angola are particularly important as a centre of both species richness and endemism of plants and vertebrates including mammals (Carleton et al. 2015). We suggest that future work should target more intensive surveys of small mammals in the central and western Angolan highlands to verify the presence and conservation status of threatened and/or endemic small mammal taxa.

\section{Acknowledgements}

This study was fully supported and funded by the National Geographic Society through the Okavango Wilderness Project, under the logistical support of the Wild Bird Trust. We thank the Angolan National Institute for Biodiversity and Conservation Areas (INBAC) for permission to conduct research and collect mammals in Angola [Permit Numbers 34/INBAC.MINAMB/ 2016 and 35/INBAC.MINAMB/2016]. Thanks are also due to Kerllen Costa, Kirstin Wimberger, Chris Boyes and Werner Conradie for their assistance with the camera trapping surveys and small mammal collection. PJT acknowledges the support of the National Research Foundation and Department of Science and Technology through the South African Research Chair on Biodiversity Value and Change, hosted by University of Venda and co-hosted by the Centre for Invasion Biology at Stellenbosch University.

\section{References}

ACR (2016) African Chiroptera Report. 2016. AfricanBats, Pretoria, 918 pp.

Altman J, Combes SL, Alberts SC (2013) Papio cynocephalus. Yellow baboon. In: Butynski TM, Kingdon J, Kalina J (Eds) Mammals of Africa. Volume II: Primates. Bloomsbury Publishing, London, 228-232.

Angelici FM, Gaubert P (2013) Genetta maculata Large-spotted Genet (Blotched Genet). In: Kingdon J, Hoffmann M (Eds) The Mammals of Africa. Volume V: Carnivores, Pangolins,

Equids and Rhinoceroses. Bloomsbury, London, UK, 232-236.

Angelici FM, Do Linh San E (2015) Crossarchus ansorgei. The IUCN Red List of Threatened Species 2015: e.T41594A45205422. http://dx.doi.org/10.2305/IUCN.UK.2015-4. RLTS.T41594A45205422.en [accessed 26.II.2018]

Angelici FM, Gaubert P, Do Linh San E (2016) Genetta maculata. The IUCN Red List of Threatened Species 2016: e.T41699A45218948. http://dx.doi.org/10.2305/IUCN. UK.2016-1.RLTS.T41699A45218948.en [accessed 23.II.2018] 
Asher RJ, Maree S, Bronner G, Bennett NC, Bloomer P, Czechowski P, Meyer M, Hofreiter M (2010) A phylogenetic estimate for golden moles (Mammalia, Afrotheria, Chrysochloridae). BMC Evolutionary Biology 10: 69. https://doi.org/10.1186/1471-2148-10-69

Barclay RMR (1999) Bats are not birds - a cautionary note on using echolocation calls to identify bats. Journal of Mammalogy 80: 290-296. https://doi.org/10.2307/1383229

Baum DA (1995) The comparative pollination and floral biology of Baobabs (Adansonia Bombacaceae) Annals of the Missouri Botanical Garden 82(2): 322-348. https://doi. org/10.2307/2399883

Beaman RS, Cellinese N (2012) Mass digitization of scientific collections: New opportunities to transform the use of biological specimens and underwrite biodiversity science. ZooKeys 209: 7-17. https://doi.org/10.3897/zookeys.209.3313

Bearder S (2016) Galagoides demidoff. The IUCN Red List of Threatened Species 2016: e.T40649A95541498. http://dx.doi.org/10.2305/IUCN.UK.2016-1.RLTS. T40649A95541498.en [accessed 26.II.2018]

Bearder S, Svoboda NS (2013) Otolemur crassicaudatus. Large-eared greater Galago. In: Butynski TM, Kingdon J, Kalina J (Eds) Mammals of Africa. Volume II: Primates. Bloomsbury Publishing, London, 409-413.

Begg C, Begg K, Kingdon J (2013) Mellivora capensis Ratel (Honey Badger). In: Kingdon J, Hoffmann M (Eds) The Mammals of Africa. Volume V: Carnivores, Pangolins, Equids and Rhinoceroses. Bloomsbury, London, UK, 119-125.

Bocian CM, Anderson J (2013) Colobus angolensis: Angola colobus (Angola black and white colobus, Angola pied colobus). In: Butynski TM, Kingdon J, Kalina J (Eds) Mammals of Africa. Volume II: Primates. Bloomsbury Publishing, London, 103-109.

Burgin CJ, Colella JP, Kahn PL, Upham NS (2018) How many species of mammals are there? Journal of Mammalogy 99: 1-14. https://doi.org/10.1093/jmammal/gyx147

Butynski TM, Kingdon J, Kalina J, (2013) Mammals of Africa. Volume II: Primates. Bloomsbury Publishing, London, 560 pp.

Carleton MD, Banasiak RA, Stanley WT (2015) A new species of the rodent genus $H y$ lomyscus from Angola, with a distributional summary of the $H$. anselli species group (Muridae: Murinae: Praomyini). Zootaxa 4040: 101-128. https://doi.org/10.11646/ zootaxa.4040.2.1

Coetzer W (2012) A new era for specimen databases and biodiversity information management in South Africa. Biodiversity Informatics 8: 1-11. https://doi.org/10.17161/bi.v8i1.4263

Cooper-Bohannon R, Rebelo H, Jones G, Cotterill F, Monadjem A, Schoeman MC, Taylor P, Park K (2016) Predicting bat distributions and diversity hotspots in southern Africa. Hystrix 27(1). https://doi.org/10.4404/hystrix-27.1-11722

Cotterill FP, Taylor PJ, Gippoliti S, Bishop JM, Groves CP (2014) Why one century of phenetics is enough: response to "are there really twice as many bovid species as we thought?" Systematic Biology 63(5): 819-832. https://doi.org/10.1093/sysbio/syu003

Cotterill FPD, Groves CP, Taylor PJ (2017) Taxonomy: refine rather than stabilize. Nature 547: 162. https://doi.org/10.1038/547162d

Cowlishaw G (2013) Papio ursinus. Chacma baboon. In: Butynski TM, Kingdon J, Kalina J (Eds) Mammals of Africa. Volume II: Primates. Bloomsbury Publishing, London, 225-228. 
Crawford-Cabral J (1986) A list of Angolan Chiroptera with notes on their distribution. Garcia de Orta, Série de Zoologia, Lisboa 13: 7-48.

Crawford-Cabral J (1998) The Angola rodents of the superfamily Muroidea. An account on their distribution. Estudos Ensaios e Documentos, 161. Instituto de Investigação Científica Tropical. Lisboa, 222 pp.

Crawford-Cabral J (2013) Genetta angolensis Miombo Genet. In: Kingdon J., Hoffmann M (Eds) The Mammals of Africa. Volume V: Carnivores, Pangolins, Equids and Rhinoceroses. Bloomsbury, London, UK, 218-220.

Crawford-Cabral J, Simóes AP (1987) Distributional data and notes on Angolan carnivores (Mammalia: Carnivora) I - Small and medium-sized species. Garcia de Orta, Série de Zoologia 14: 3-27.

Crawford-Cabral J, Mesquitela LM (1989) Índice toponímico de colheitas zoológicas em Angola. Estudos Ensaios e Documentos, 151. Instituto de Investigação Científica Tropical. Lisboa.

Crawford-Cabral J, Simóes AP (1988) Distributional data and notes on Angolan carnivores (Mammalia: Carnivora). Volume II: Larger species. Garcia de Orta, Série de Zoologia 15: 9-20.

Crawford-Cabral J, Veríssimo LN (2005) The ungulate fauna of Angola. Systematic list, distribution maps, database report. Estudos Ensaios e Documentos, 163. Instituto de Investigação Científica Tropical, Lisboa.

Creel S (2013) Helogale parvula. Dwarf Mongoose. In: Kingdon J, Hoffmann M (Eds) The Mammals of Africa. Volume V: Carnivores, Pangolins, Equids and Rhinoceroses. Bloomsbury Publishing, London, UK, 368-373.

De Graaff G (1981) The rodents of Southern Africa. Butterworths, Durban, 267pp.

Delibes M, Gaubert P (2013) Genetta genetta Common Genet (Small-spotted Genet). In: J. Kingdon J, Hoffmann M (Eds) The Mammals of Africa. Volume V: Carnivores, Pangolins, Equids and Rhinoceroses. Bloomsbury, London, UK, 223-229.

Denys C, Taylor PJ, Aplin KP, Burgin CJ, Fabre P-H, Haslauer R, Woinarski JCZ, Breed WG, Menzies JI (2017) Family Muridae (True Mice and Rats, Gerbils and relatives). In: Wilson DE, Lacher Jr TE, Mittermeier RA (Eds) Handbook of the Mammals of the World. Volume 7: Rodents II. Lynx Edicions, Barcelona, 536-884.

Do Linh San E, Maddock AH, Gaubert P, Palomares F (2016) Herpestes ichneumon. The IUCN Red List of Threatened Species 2016: e.T41613A45207211. http://dx.doi.org/10.2305/ IUCN.UK.2016-1.RLTS.T41613A45207211.en [accessed 26.II.2018]

Du Toit N, van Vuuren BJ, Matthee S, Matthee CA (2012) Biome specificity of distinct genetic lineages within the four-striped mouse Rhabdomys pumilio (Rodentia: Muridae) from southern Africa with implications for taxonomy. Molecular Phylogenetics and Evolution 65: 75-86. https://doi.org/10.1016/j.ympev.2012.05.036

Ehardt CL (2013) Chlorocebus torquatus Red-capped Mangabey. In: Butynski TM, Kingdon J, Kalina J (Eds) The Mammals of Africa. Volume II: Primates. Bloomsbury Publishing, London UK, 186-189.

Estes RD (2013) Hippotragus niger Sable Antelope. In: Kingdon J, Hoffmann M (Eds) The Mammals of Africa. Volume VI: Pigs, Hippopotamuses, Chevrotain, Giraffes, Deer and Bovids. Bloomsbury, London, 556-565. 
Fritz H, Bourgarel M (2013) Aepycerus melampus Impala. In: Kingdon J, Hoffmann M (Eds) The Mammals of Africa. Volume VI: Pigs, Hippopotamuses, Chevrotain, Giraffes, Deer and Bovids. Bloomsbury, London, 480-487.

Funston P, Henschel P, Petracca L, Maclennan S, Whitesell C, Fabiano E, Castro I (2017) The distribution and status of lions and other large carnivores in Luengue-Luiana and Mavinga National Parks, Angola. KAZA TFCA Secretariat, Kasane, Botswana.

Gaubert P (2013) Family Nandiniidae Two-spotted Palm Civet. In: Kingdon J, Hoffmann M (Eds) The Mammals of Africa.Volume V: Carnivores, Pangolins, Equids and Rhinoceroses. Bloomsbury, London, 138-139.

Gaubert P, Dunham AE (2013) Genetta pardina Pardine Genet (West African Large-spotted Genet). In: Kingdon J, Hoffmann M (Eds) The Mammals of Africa. V. Carnivores, Pangolins, Equids and Rhinoceroses. Bloomsbury, London, 237-238.

Gaubert P, Fischer C, Hausser Y, Do Linh San E (2016) Genetta angolensis. The IUCN Red List of Threatened Species 2016: e.T41696A45218468. http://dx.doi.org/10.2305/IUCN. UK.2016-1.RLTS.T41696A45218468.en [accessed 28.II.2018]

Garnett ST, Christidis L (2017) Taxonomy anarchy hampers conservation. Nature 546: 25-27. https://doi.org/10.1038/546025a

Gilchrist JS, Do Linh San E (2016) Mungos mungo. The IUCN Red List of Threatened Species 2016: e.T41621A45208886. http://dx.doi.org/10.2305/IUCN.UK.2016-1.RLTS. T41621A45208886.en [accessed 26.II.2018]

Gippoliti S, Groves CP (2012) “Taxonomic inflation” in the historical context of mammalogy and conservation. Hystrix 23(2): 8-11. https://doi.org/10.4404/hystrix-23.2-8685

GBIF.org (2017) GBIF Occurrence Download https://doi.org/10.15468/dl.aztnnq [downloaded 18 December 2017]

Goossens B, Funk SM, Vidal C, Latour S, Jamart A, Ancrenaz M, Wickings EJ, Tutin CEG, Bruford MW (2002) Measuring genetic diversity in translocation programmes: principles and application to a chimpanzee release project. Animal Conservation 5: 225-236. https:// doi.org/10.1017/S1367943002002275

Gosling LM, Capellini I (2013) Alcelaphus buselaphus Hartebeest. In: Kingdon J, Hoffmann M (Eds) The Mammals of Africa. Volume VI: Pigs, Hippopotamuses, Chevrotain, Giraffes, Deer and Bovids. Bloomsbury, London, 511-526.

Groves CP (2001) Primate Taxonomy. Smithsonian Institution Press, Washington DC, 350 pp. Groves CP, Grubb P (2011) Ungulate Taxonomy. The Johns Hopkins University Press, Baltimore, MD, $336 \mathrm{pp}$.

Groves CP, Cotterill FDP, Gippoliti S, Robovský J, Roos C, Taylor PJ, Zinner D (2017) Species definitions and conservation: a review and case studies from African mammals. Conservation Genetics 18(6): 1247-1256. https://doi.org/10.1007/s10592-017-0976-0

Happold DCD (2013) Mammals of Africa, Volume III: Rodents, Hares and Rabbits. Bloomsbury Publishing, London, 784 pp.

Happold M, Happold DCD (2013) Mammals of Africa, Volume IV: Hedgehogs, Shrews and Bats. Bloomsbury Publishing, London, 800 pp.

Hayman RW (1963) Mammals from Angola mainly from Lunda district. Publicaçóes culturais. Companhia de Diamantes de Angola. Lisboa 66: 81-140. 
Heller R, Frandsen P, Lorenzen ED, Siegismund HR (2013) Are there really twice as many bovid species as we thought? Systematic Biology 62(3): 490-493. https://doi. org/10.1093/sysbio/syt004

Heller R, Frandsen P, Lorenzen ED, Siegismund HR (2014) Is diagnosability an indicator of speciation? Response to "Why one century of phenetics is enough". Systematic Biology 63(5): 833-837. https://doi.org/10.1093/sysbio/syu034

Herkt KMB, Barnikel G, Skidmore AK, Fahr J (2016) A high-resolution model of bat diversity and endemism for continental Africa. Ecological Modelling 320: 9-28. https://doi. org/10.1016/j.ecolmodel.2015.09.009

Hill JE, Carter TD (1941) The mammals of Angola, Africa. Bulletin of the American Museum of Natural History 78: 1-211.

Hoffmann M, Hilton-Taylor C (2008) Papio ursinus (errata version published in 2016). The IUCN Red List of Threatened Species 2008: e.T16022A99710253. http://dx.doi. org/10.2305/IUCN.UK.2008.RLTS.T16022A5356469.en [accessed 25.II.2018]

Hoffmann M, Taylor ME (2013) Herpestes sanguineus Slender Mongoose. In: Kingdon J, Hoffmann M (Eds) The Mammals of Africa. Volume V: Carnivores, Pangolins, Equids and Rhinoceroses. Bloomsbury, London, 314-319.

Jew EKK, Dougill AJ, Sallu SM, O’Connell J, Benton TG (2016) Miombo woodland under threat: Consequences for tree diversity and carbon storage. Forest Ecology and Management 361: 144-153. doi:10.1016/j.foreco.2015.11.011

Kingdon J (2016) Papio kindae. The IUCN Red List of Threatened Species 2016: e.T136848A92251482. http://dx.doi.org/10.2305/IUCN.UK.2016-1.RLTS.T136848A92251482.en [accessed 25.II.2018]

Kingdon J, Butynski TM (2008) Chlorocebus aethiops. The IUCN Red List of Threatened Species 2008: e.T4233A10695029. http://dx.doi.org/10.2305/IUCN.UK.2008.RLTS. T4233A10695029.en [accessed 25.II. 2018]

Kingdon J, Butynski TM, De Jong Y (2016) Papio cynocephalus. The IUCN Red List of Threatened Species 2016: e.T92250442A92250811. http://dx.doi.org/10.2305/IUCN. UK.2016-1.RLTS.T92250442A92250811.en [ accessed 25.II.2018]

Kingdon J, Gippoliti S, Butynski TM, Lawes MJ, Eeley H, Lehn C, De Jong Y (2008) Cercopithecus mitis. The IUCN Red List of Threatened Species 2008: e.T4221A10676022. http:// dx.doi.org/10.2305/IUCN.UK.2008.RLTS.T4221A10676022.en [accessed 25.II.2018]

Kingdon J, Happold D, Butynski T, Hoffmann M, Happold M, Kalina J (2013a) Mammals of Africa (6 volumes). Bloomsbury Publishing, London.

Kingdon J, Happold D, Hoffmann M, Butynski T, Happold M, Kalina J (2013b) Mammals of Africa. Volume I: Introductory Chapters and Afrotheria. Bloomsbury Publishing, London, 351 pp.

Kingdon J, Hoffmann M (2013a) Mammals of Africa. Volume 5: Carnivores, Pangolins, Equids and Rhinoceroses. Bloomsbury Publishing, London, 560 pp.

Kingdon J, Hoffmann M (2013b) The Mammals of Africa. Volume 6. Pigs, Hippopotamuses, Chevrotain, Giraffes, Deer and Bovids. Bloomsbury, London, 704 pp.

Lamb JM, Taylor PJ, Eiseb S, Downs S (2014) Increased geographic sampling reveals considerable new genetic diversity in the morphologically conservative African Pygmy Mice (Genus 
Mus; Subgenus Nannomys). Mammalian Biology 79(1): 24-35. https://doi.org/10.1016/j. mambio.2013.08.010

Lawes MJ, Cords M, Lehn C (2013) Cercopithecus mitis Profile. In: Butynski TM, Kingdon J, Kalina J (Eds) Mammals of Africa. Volume II: Primates. Bloomsbury Publishing, London, 354-362.

Macdonald DW (2013) Suricata suricatta Meerkat (Suricate). In: Kingdon J, Hoffmann M (Eds) The Mammals of Africa. V. Carnivores, Pangolins, Equids and Rhinoceroses. Bloomsbury, London, 347-352.

Mammal Diversity Database (2018) American Society of Mammalogists. https://mammaldiversity.org/ [accessed 7.II.2018]

Mann GKH, O’Riain MJ, Parker DM (2015) The road less travelled: assessing species-specific detection probabilities with camera traps in an arid biodiversity hotspot. Biodiversity and Conservation 24: 531-545. https://doi.org/10.1007/s10531-014-0834-z

Meester JAJ, Setzer HW (1971) The Mammals of Africa - An Identification Manual. Smithsonian Institution Press, Washington DC.

Mills MS, Olmos F, Melo M, Dean WRJ (2011) Mount Moco: its importance to the conservation of Swierstra's Francolin Pternistis swierstrai and the Afromontane avifauna of Angola. Bird Conservation International 21(2): 119-133. https://doi.org/10.1017/ S0959270910000493

Mills MS, Melo M, Vaz A (2013) The Namba mountains: new hope for Afromontane forest birds in Angola. Bird Conservation International 23(2): 159-167. https://doi.org/10.1017/ S095927091200024X

Mills MGL (2015) Living near the edge: A review of the ecological relationships between large carnivores in the arid Kalahari. African Journal of Wildlife Research 45: 127-137. https:// doi.org/10.3957/056.045.0127

Mittermeier RA, Rylands AB, Wilson DE (2013) Handbook of the Mammals of the World. Volume III: Primates. Lynx Edicions, Barcelona, 556 pp.

Monadjem A, Taylor PJ, Cotterill FPD, Schoeman MC (2010a) Bats of southern and southcentral Africa: A Biogeographic and Taxonomic Synthesis. Wits University Press, Johannesburg, $596 \mathrm{pp}$.

Monadjem A, Schoeman MC, Reside A, Pio DV, Stoffberg S, Bayliss J, Cotterill FPD, Curran M, Kopp M, Taylor PJ (2010b) A recent inventory of the bats of Mozambique with documentation of seven new species for the country. Acta Chiropterologica 12(2): 371-391. https://doi.org/10.3161/150811010X537963

Monadjem A, Taylor PJ, Denys C, Cotterill FPD (2015) Rodents of Sub-Saharan Africa: a biogeographic and taxonomic synthesis. De Gruyter, Berlin, 1092 pp. https://doi. org/10.1515/9783110301915

Monadjem A, Shapiro JT, Mtsetfwa F, Reside AE, McCleery RA (2017) Acoustic call library and detection distances for bats of Swaziland. Acta Chiropterologica 19(1): 175-187. https://doi.org/10.3161/15081109ACC2017.19.1.014

Musser GG, Carleton MD (2005) Superfamily Muroidea. In: Wilson DE, Reeder DM (Eds) Mammal species of the world: a taxonomic and geographic reference $3^{\text {rd }}$ edition. John Hopkins University Press, Baltimore, 894-1531. 
Oates JF, Hart J, Groves CP, Butynski TM (2008a) Cercopithecus ascanius. The IUCN Red List of Threatened Species 2008: e.T4212A10654844. http://dx.doi.org/10.2305/IUCN. UK.2008.RLTS.T4212A10654844.en [accessed 25.II.2018]

Oates JF, Groves CP, Ehardt C (2008b) Lophocebus albigena. The IUCN Red List of Threatened Species 2008: e.T12309A3332270. http://dx.doi.org/10.2305/IUCN.UK.2008.RLTS. T12309A3332270.en [accessed 25.II.2018]

Oates JF, Gippoliti S, Bearder S (2008c) Cercopithecus cephus. The IUCN Red List of Threatened Species 2008: e.T4214A10664683. http://dx.doi.org/10.2305/IUCN.UK.2008. RLTS.T4214A10664683.en [accessed 26.II.2018]

O’Brien TG, Kinnaird MF, Wibisono HT (2003) Crouching tigers, hidden prey: Sumatran tiger and prey populations in a tropical forest landscape. Animal Conservation 6: 131-139. https://doi.org/10.1017/S1367943003003172

Pimley ER, Bearder SK (2013) Perodicticus potto. In: Butynski TM, Kingdon J, Kalina J (Eds) The Mammals of Africa. Volume II: Primates. Bloomsbury Publishing, London, 393-399.

Pullen S, Bearder SK (2013) Galago moholi. Southern Lesser Galago (South African Lesser Galago). In: Butynski TM, Kingdon J, Kalina J (Eds) Mammals of Africa. Volume II: Primates. Bloomsbury Publishing, London, 430-433.

Ray JC (2013) Civettictis civetta African civet. In: Kingdon J, Hoffmann M (Eds) The Mammals of Africa. Volume V: Carnivores, Pangolins, Equids and Rhinoceroses. Bloomsbury, London, 255-259.

Reed-Smith J, Jacques H, Somers MJ (2015) Hydrictis maculicollis. The IUCN Red List of Threatened Species 2015: e.T12420A21936042. http://dx.doi.org/10.2305/IUCN. UK.2015-2.RLTS.T12420A21936042.en [accessed 23.II.2018]

Rodrigues P, Figueira R, Vaz Pinto P, Araújo MB, Beja P (2015) A biogeographical regionalization of Angolan mammals. Mammal Review 45: 103-116. https://doi.org/10.1111/ mam. 12036

Rovero F, Marshall AR (2009) Camera trapping photographic rate as an index of density in forest ungulates. Journal of Applied Ecology 46: 1011-1017. https://doi.org/10.1111/ j.1365-2664.2009.01705.x

Rovero F, Martin E, Rosa M, Ahumada JA, Spitale D (2014) Estimating species richness and modelling habitat preferences of tropical forest mammals from camera trap data. PLoS ONE 9(7): e103300. https://doi.org/10.1371/journal.pone.0103300

Rydell J, Nyman S, Eklöf J, Jones G, Russo D (2017) Testing the performances of automated identification of bat echolocation calls: A request for prudence. Ecological Indicators 78: 416-420. https://doi.org/10.1016/j.ecolind.2017.03.023

Sarmiento EE (2013) Chlorocebus cynosuros, Malbrouck Monkey. In: Butynski TM, Kingdon J, Kalina J (Eds) Mammals of Africa. Volume II: Primates. Bloomsbury Publishing, London, 284-286.

Schmidt DF, Ludwig CA, Carleton MD (2008) The Smithsonian Institution African Mammal Project (1961-1972). An Annotated Gazetteer of Collecting Localities and Summary of Its 
Taxonomic and Geographic Scope. Smithsonian Institution Scholarly Press, Washington DC. https://doi.org/10.5479/si.00810282.628

Schoeman MC, Cotterill FPD, Taylor PJ, Monadjem A (2013) Using potential distributions to explore environmental correlates of bat species richness in southern Africa: effects of model selection and taxonomy. Current Zoology 59 (3): 279-293. https://doi.org/10.1093/ czoolo/59.3.279

Shultz S Roberts D (2013) Dendrohyrax dorsalis Western Tree Hyrax. In: Kingdon JS, Happold D.C.D., Hoffmann M, Butynski TM, Happold M and Kalina J (Eds), The Mammals of Africa. Volume 1: Introductory Chapters and Afrotheria. London. Bloomsbury Publishing, London, 155-157.

Soberón J, Peterson AT (2004) Biodiversity informatics: managing and applying primary biodiversity data. Philosophical Transactions of The Royal Society B Biological Sciences 359: 689-698. https://doi.org/10.1098/rstb.2003.1439

Somers MJ, Nel JAJ (2013). Aonyx capensis. In: Kingdon J, Hoffmann M (Eds) Mammals of Africa. Volume V: Carnivores, Pangolins, Equids and Rhinoceroses. Bloomsbury Publishing, London, 104-108.

Stein A, Fuller T, Marker L (2008) Opportunistic use of camera traps to assess habitat-specific mammal and bird diversity in northcentral Namibia. Biodiversity and Conservation 17: 3579-3587. https://doi.org/10.1007/s10531-008-9442-0

Struhsaker T, Oates JF, Hart J, Butynski TM (2008) Cercopithecus neglectus. The IUCN Red List of Threatened Species 2008: e.T4223A10680717. http://dx.doi.org/10.2305/IUCN. UK.2008.RLTS.T4223A10680717.en [accessed 25.II.2018]

Stuart C, Stuart T (2013a) Paracynictis selousi Selous's Mongoose. In: Kingdon J, Hoffmann M (Eds) The Mammals of Africa. Volume V: Carnivores, Pangolins, Equids and Rhinoceroses. Bloomsbury Publishing, London, 339-341.

Stuart C, Stuart T (2013b) Ictonyx striatus Zorilla. In: Kingdon J, Hoffmann M (Eds) The Mammals of Africa. Volume V: Carnivores, Pangolins, Equids and Rhinoceroses. Bloomsbury Publishing, London, 93-97.

Stuart C, Stuart T (2013c) Poecilogale albinucha African Striped Weasel. In: Kingdon J, Hoffmann M (Eds) The Mammals of Africa. Volume V: Carnivores, Pangolins, Equids and Rhinoceroses. Bloomsbury Publishing, London, 98-101.

Syampungani S, Chirwa PW, Akinnifesi FK, Sileshi G, Ajayi OC (2009) The miombo woodlands at the cross roads: Potential threats, sustainable livelihoods, policy gaps and challenges. Natural Resources Forum 33(2): 150-159. https://doi.org/10.1111/j.14778947.2009.01218.x

Taylor A, Lehmann T (2015) Orycteropus afer. The IUCN Red List of Threatened Species 2015: e.T41504A21286437. http://dx.doi.org/10.2305/IUCN.UK.2015-2.RLTS. T41504A21286437.en [accessed 26.II.2018]

Taylor ME (2013b) Herpestes ochraceus Somali Slender Mongoose. In: Kingdon J, Hoffmann M (Eds) The Mammals of Africa. Volume V: Carnivores, Pangolins, Equids and Rhinoceroses. Bloomsbury, London, 310-311. 
Taylor ME (2013c) Herpestes flavescens Kaokoveld Slender Mongoose (Angolan Slender Mongoose). In: Kingdon J, Hoffmann M (Eds) The Mammals of Africa. Volume V: Carnivores, Pangolins, Equids and Rhinoceroses. Bloomsbury, London, 304-306.

Taylor PJ, Sowler S, Schoeman MC, Monadjem A (2013) Diversity of bats in the Soutpansberg and Blouberg Mountains of northern South Africa: complimentarity of acoustic and nonacoustic survey methods. South African Journal of Wildlife Research 43(1): 12-26. https:// doi.org/10.3957/056.043.0117

Taylor PJ (2013a) Cynictis penicillata Yellow Mongoose. In: Kingdon J, Hoffmann M (Eds) The Mammals of Africa. Volume V: Carnivores, Pangolins, Equids and Rhinoceroses. Bloomsbury, London, 334-339.

Taylor PJ, Munyai A, Gaigher I, Baxter R (2015) Afromontane small mammals do not follow the hump-shaped rule: elevational variation in a tropical biodiversity hotspot (Soutpansberg Mountains, South Africa). Journal of Tropical Ecology 31(1): 37-48. https://doi. org/10.1017/S0266467414000613

Tobler M, Carrillo-Percastegui S, Pitman R, Mares R, Powell G (2008) An evaluation of camera traps for inventorying large- and medium-sized terrestrial rainforest mammals. Animal Conservation 11: 169-178. https://doi.org/10.1111/j.1469-1795.2008.00169.x

Van Rompaey H, Colyn M (2013a) Bdeogale nigripes Black-legged Mongoose. In: Kingdon J, Hoffmann M (Eds) The Mammals of Africa. Volume V: Carnivores, Pangolins, Equids and Rhinoceroses. Bloomsbury, London, 326-328.

Van Rompaey H, Colyn M (2013b) Crossarchus ansorgei Ansorge's Cusimanse (Angolan Cusimanse)). In: Kingdon J, Hoffmann M (Eds) The Mammals of Africa. Volume V: Carnivores, Pangolins, Equids and Rhinoceroses. Bloomsbury, London, 376-378.

Van Rompaey H, Colyn M (2013c) Genetta servalina Servaline Genet. In: Kingdon J, Hoffmann M (Eds) The Mammals of Africa. Volume V: Carnivores, Pangolins, Equids and Rhinoceroses. Bloomsbury, London, 242-245.

Vaz Pinto P (2006). Hybridisation in Giant Sable: a conservation crisis in a critically endangered Angolan icon. IUCN/SSC Antelope Specialist Group. Gnusletter 25: 14-16.

Vaz Pinto P (2018) Evolutionary history of the critically endangered giant sable antelope (Hippotragus niger variani). Insights into its phylogeography, population genetics, demography and conservation. PhD Thesis. University of Porto, Porto, Portugal.

Wieczorek J, Bloom D, Guralnick R, Blum S, Doring M, Giovanni R, Robertson T, Vieglais D (2012) Darwin Core: an evolving community-developed biodiversity data standard. PLoS ONE 7: e29715. https://doi.org/10.1371/journal.pone.0029715

Williams SD (2013) Equus grevyi Grevy's zebra. In: Kingdon J, Hoffmann M (Eds) The Mammals of Africa. Volume V: Carnivores, Pangolins, Equids and Rhinoceroses. Bloomsbury, London, 422-428.

Wilson DE, Reeder DM (2005) Mammal Species of the World. A Taxonomic and Geographic Reference. Johns Hopkins University Press, Baltimore.

Zachos FE, Apollonio M, Bärmann EV, Festa-Bianchet M, Göhlich U, Habel JC, Haring E, Kruckenhauser L, Lovari S, McDevitt AD, Pertoldi C, Rössner GE, Sánchez-Villagra MR, Scandura M, Suchentrunk F (2013) Species inflation and taxonomic artefacts - a critical 
comment on recent trends in mammalian classification. Mammalian Biology 78: 1-6. https://doi.org/10.1016/j.mambio.2012.07.083

\section{Supplementary material I}

\section{Test list of species names}

Authors: Peter J. Taylor, Götz Neef, Mark Keith, Sina Weier, Ara Monadjem, Daniel M. Parker

Data type: species data

Copyright notice: This dataset is made available under the Open Database License (http://opendatacommons.org/licenses/odbl/1.0/). The Open Database License $(\mathrm{ODbL})$ is a license agreement intended to allow users to freely share, modify, and use this Dataset while maintaining this same freedom for others, provided that the original source and author(s) are credited.

Link: https://doi.org/10.3897/zookeys.779.25964.suppl1

\section{Supplementary material 2}

\section{Labeled images of example sonograms of each bat species identified}

Authors: Peter J. Taylor, Götz Neef, Mark Keith, Sina Weier, Ara Monadjem, Daniel M. Parker

Data type: species data

Copyright notice: This dataset is made available under the Open Database License (http://opendatacommons.org/licenses/odbl/1.0/). The Open Database License $(\mathrm{ODbL})$ is a license agreement intended to allow users to freely share, modify, and use this Dataset while maintaining this same freedom for others, provided that the original source and author(s) are credited.

Link: https://doi.org/10.3897/zookeys.779.25964.suppl2 


\section{Supplementary material 3}

Excel spreadsheet of occurrence data from cleaned GBIG search of Angolan mammal Authors: Peter J. Taylor, Götz Neef, Mark Keith, Sina Weier, Ara Monadjem, Daniel M. Parker

Data type: occurence

Copyright notice: This dataset is made available under the Open Database License (http://opendatacommons.org/licenses/odbl/1.0/). The Open Database License $(\mathrm{ODbL})$ is a license agreement intended to allow users to freely share, modify, and use this Dataset while maintaining this same freedom for others, provided that the original source and author(s) are credited.

Link: https://doi.org/10.3897/zookeys.779.25964.suppl3 